مسقل الإصلاح السياسيفي مصر : الواقع والطموح

\author{
ميتاق خير الله جلود \\ مدرس مساعد/قسم الدر اسات السياسية و الإستر اتيجية \\ مركز الدراسات الإقليمية/ جامعة الموصل.
}

مستخلص البحث

تعد قضية الإصلاح في مصر مسألة ملحة كما هو الحال فــي بــاقي

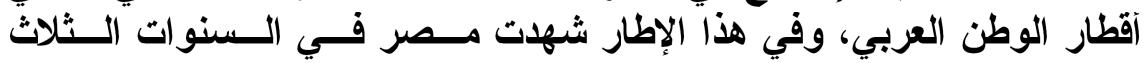

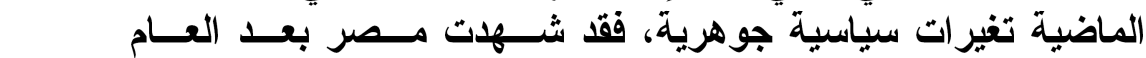

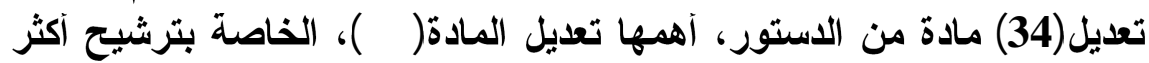

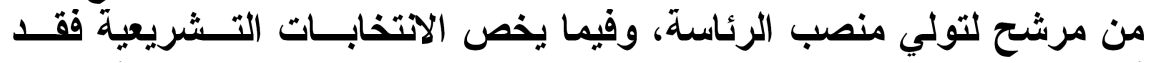

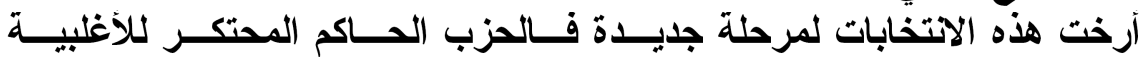

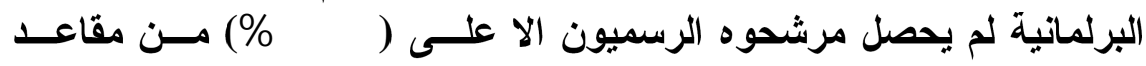

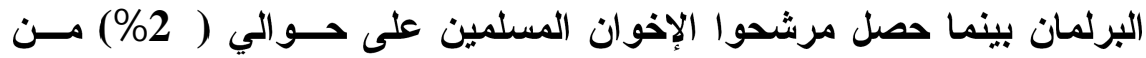

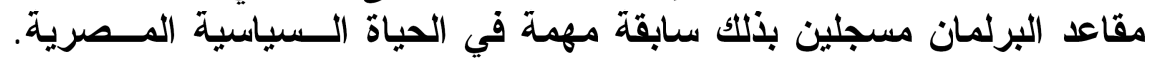

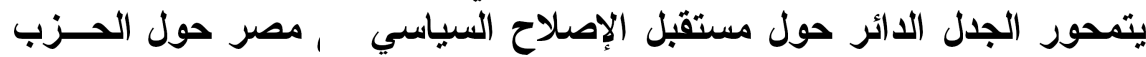

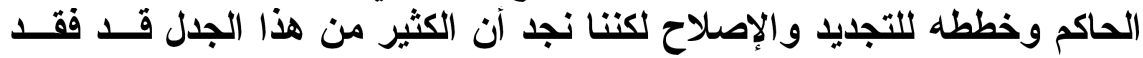

محتو اه.

olotion

تعد قضية الإصلاح في مصر مسألة ملحة كما هو الحال في باقي اقطار

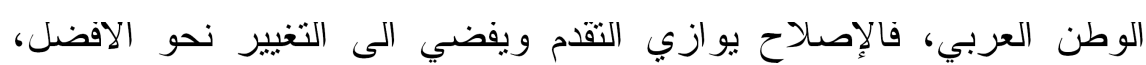


خاصة و ان العالم بتطور و الفو اصل بين دوله اصبحت شبه معدومة، فلم تعد التقليدية و الجمود وكبت الإبداع و الحريات تتلائم مع منطلبات العصر . لقد شهدت مصر في السنوات النتاث الماضية تغيرات سياسبة جوهرية، و لاسبما موضوع نرشيح اكتر من مرشح لتولي منصب الرئاسة، فضلا عن

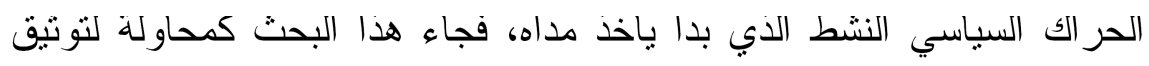

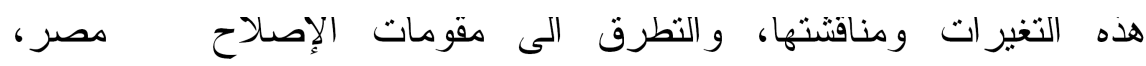
و استشر اف مستقبله على المدى القريب، فكان لابد من فهم طبيعة النظام الحاكم من خلال النطرق الى خلفية النظام المصري وتجربته البرلمانية الر ائدة في الوطن العربي، فضلا عن مظاهر الاصلاح التي اخذت مداها في السنوات القلبلة الماضية، وقد تم ذلك في عدة محاور هي: ا__طبيعة نظام الحكم r_إلتغير ات التي شهدتها مصر بهدف الإصـاح السياسي "ـــــــاهر الاصلاح و التغيير ع_رؤى الاصداح بين الحزب الحاكم و المعارضة

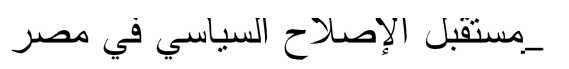

توطئه:

بعد احداث ايلول/سبتمبر I . . r ومار افقها من تغير ات على مستوى العالم، القت بظلالها على المنطقة العربية، الني بدات تتعرض الى ضغوط خارجية مطالبة بالاصلاح اضيفت الى الاصوات الداخلية، كانت مصر من الدول الني

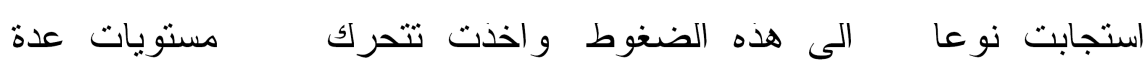

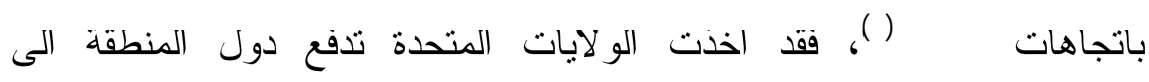


الاصلاح دفعا فاصبحنا لانسمع خطابا للرئيس الامريكي الا ويتحدث فيه عن الاصلاح في المنطقة العربية ولاسيما مصر (2)، المرتبطة بالو لايات المتحدة لألئي ارتباطا وتيقا بسبب المساعدات التي تقدمها سنويا لمصر، و التي تمارس من خلالها ضغطا على الحكومة المصرية، فضلا عن تقديم الدعم للاصوات الني تطالب بالاصلاح كايمن نور (زعيم حزب الغد) الذي طالبت بالإفر اج عنه عندما

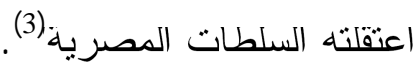
لقد وضعت تعريفات عدة للاصلاح السياسي، فقد عرفه قاموس اكسفورد بانه" تعديل او تبديل نحو الافضل في حالة الاشياء الني تعاني من النقائص

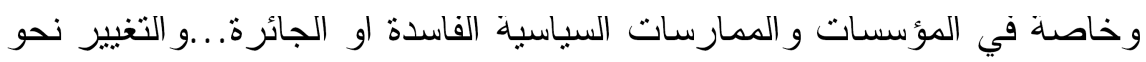
الافضل" (4) (4)

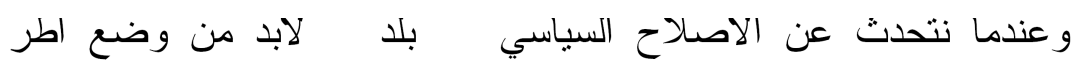
محددة لعملية الاصلاح، وفي هذا الصدد نسثرشد بتلخيص رؤية المؤتمر الذي وني

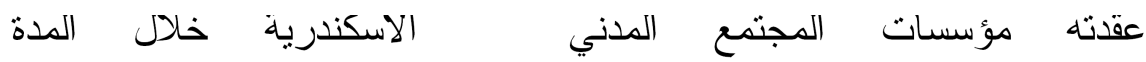
rا_عا_اذار/مارس م ع ع الذي لخص عملية الاصلاح "بالخطوات المباشرة، و غير المباشرة التي يقع عبء القيام بها على عاتق لكل من الحكومات و المجتمع المدني ومؤسسات القطاع الخاص، وذلك للسير بالمجتمعات و الدول قدما، وبناء نظم تعددية".و عندما نتحدث عن نظم تعددية، وفقا للنغير ات التقافية و الحضارية من بلد لاخر ، ولكن جوهر ها بظل و احدا(اب إصلاح بإطاره العام) و المقصود بالنظام التعددي،هو دلك النظام الدي نكون الحرية فيه هي الفيمة العليا و الاساسية بما بحقق السيادة الفعلية للشعب، من خلال التعددية السياسية التي تؤدي إلى تداول السلطة، وتقوم على احترام كلفة الحقوف في الفكر

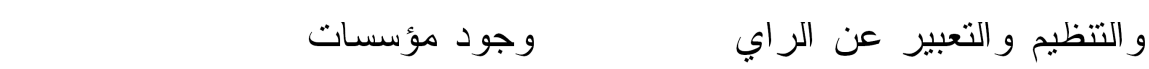


راسها المؤسسات التشريعية المنتخبة، و القضاء المستقل، و الحكومة الخاضعة

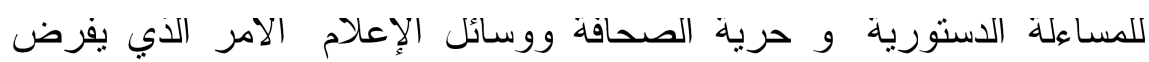

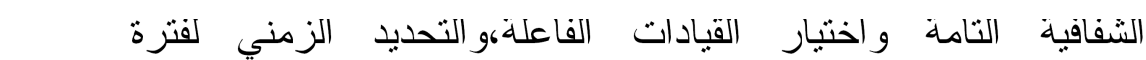
بمسؤوليتها، و التطبيق الفعلي لمبدا سبادة القانون بما لا بعرف الاستتناء مهما كانت مبررات هذا الاستتناء ودواعبه، و إلغاء القوانين الاستنتائية وقو انين الطوارئ المعمول بها في بعض البلدان العربية، و إلغاء المحاكم الاستثنائبة اباء ولياء كانت اشكالها ومسمباتها، لأنها تتنقص من النظام السياسي (5).

\section{I_بيعه نظام الحكر:}

من المتعذر تصنيف النظام السياسي المصري ضمن الانظمة الشمولية،

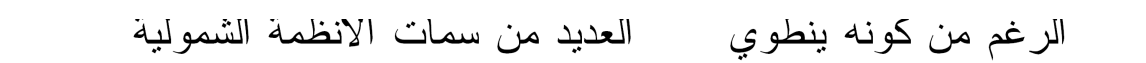
يمكن ان نعده في الوقت فهس نظاما رئاسبا او برلمانبا او مختلطا، على الرغم من انه بحنوي عله بعض سمات التعددية، وفي سياق كهذا تبدو المصطلحات الاقرب دقة في توصيف النظام المصري انه "شبه شمولي" و 'شتبه تعددي"، وربما كان اهم ما يلفت النظر في خصائص النظام المصري الحالي و الذي

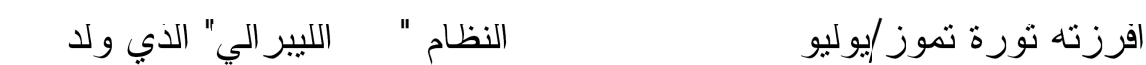

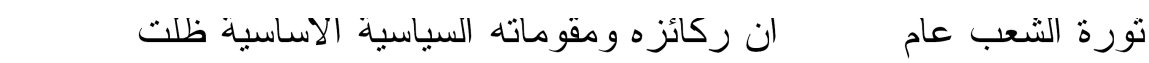
دون تغيير، على الرغم من التحولات الهائلة الني طرات على بنية المجتمع المصري، و على مجل السياسات و النوجهات الفكرية و الايديولوجية، الني تبنتها

تورة نموز /يوليو 1952 على كلفة الاصعدة، الداخلية و الخارجية (6).

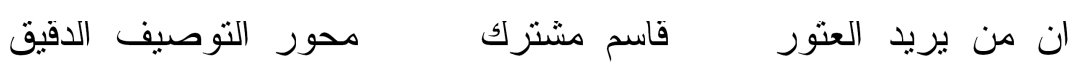

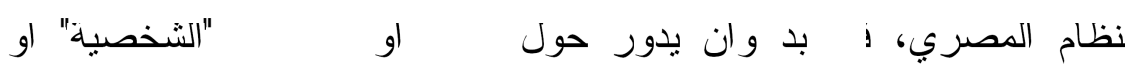


"الفرديه"؛ فالنظام كله يتمحور حول شخص و احد، هو رئيس الجمهورية، يجمع في يده اغلب الصلاحبات و السلطات، وبوسع هذا الحاكم الفرد ان يقرر على لهون

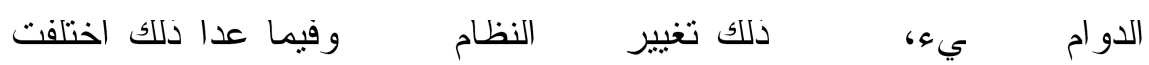
توجهات النظام باختلاف شخصية الرؤساء الذين تعاقبو ا على حكم مصر منذ تورة 190r اختلافا جو هريا، ومع ذلك فبوسع الباحث المدقق ان برصد اختلافا

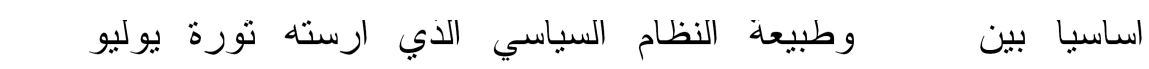

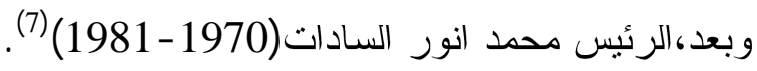
لقد عرفت مصر الحياة النيابية بدءا من عام1829 ، بتكوين " مجلس المشورة"' الذي تالف من(107) عضوا منهم (سّ) من كبار الموظفين و علماء الدين و(عr) من موظفي الاقاليم و(99) من كبار اعيان البلاد، وقد كانت طبيعة هذا المجلس اسنتارية، اما اول دسنور في مصر فقد صدر في ل شباط/فبر اير MAT من خمسين مادة، و اعتبر صدوره مناسبة وطنية احتقلت

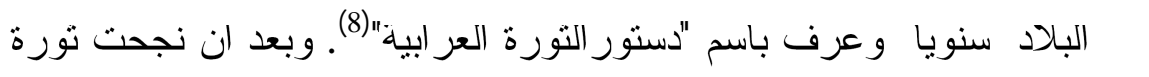

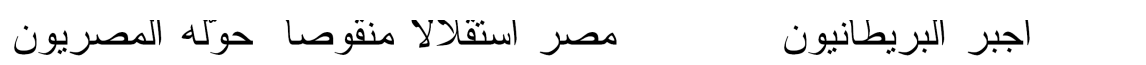
بسرعة إلى إنجاز سيلسي، بصدور دستور عام سبوا الذي دخلت به مصر

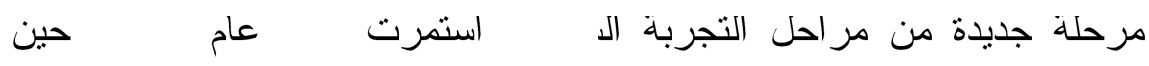
طرح على الثعب المصري عقد اجتماعي جديد بتمّ بموجبه تحقيق العدالة الاجتماعية و التتمية الاقتصادية وتحقيق حلم الوحدة العربية مقالبل تعطيل الحياة النيابية إلى حين، وقد رحَب الشعب بدلك العقد الاجتماعي الجديد (9). ففي المرحلة الناصرية (1953_1970) صدرت دساتير مؤقتة متعددة عبر لكل منها عن مرحلة مختلفة من مراحل تطور التورة، فالإعلان الدستوري مونه

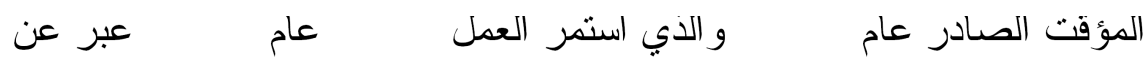


مرحلة التحول من نظام الحكم (الملكي _البرلماني) إلى نظام الحكم (الجمهوري_الرئاسي)، وكان يفترض ان يقنن دستور 1907 ويصبح دستورا دائما، غير ان دخول مصر في وحدة مع سوربا استدعى إدخال تغييرات جوهرية على هذا الدستور، مما نطلب إصدار دستور جديد عام 1901 يمكن

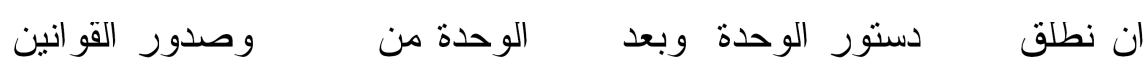

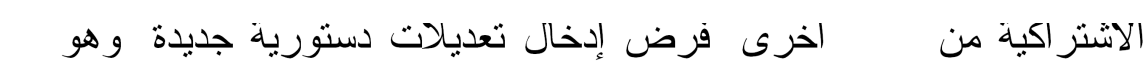

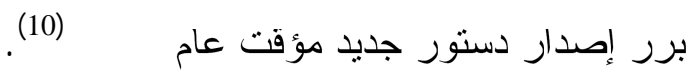

وبعد هزيمة 197V، بدا الثعب المصري بطالب بعودة الحياة النبابية،

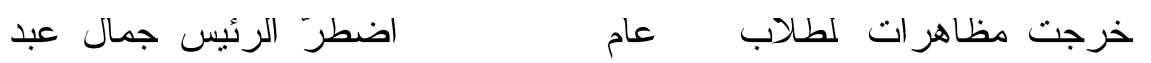

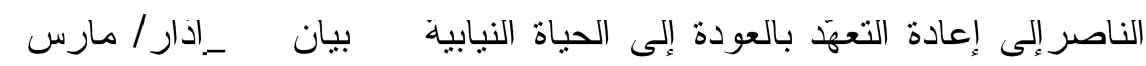
ولكن لم يتحقق ذلك الوعد(11) تم تاجيله من اجل إحداث تغيير جوهري في نظام الحكم، رغم اقتتاع الرئيس الكامل بضرورته، إلى ما بعد معركة "إز الذة

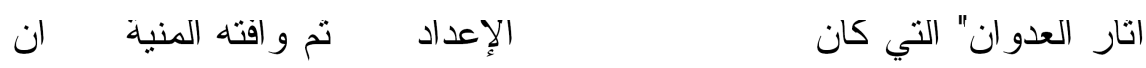
ينجز ايا من الهدفين؛ التحرير و الحياة النيابية. وفي سياق الصراع المحتدم على السلطة بين السادات وخصومه، و الذي هسمه الاول لصالحه (12)، صدر دسنور الهور I9VI المعمول به في الوقت الحاضر ، وتكفي نظرة عابرة على هذا الدسنور للدلالة على انه قام في الواقع على افتر اض اساس، وهو ان تورة $190 r$ وصلت إلى اوج نضجها وبات بوسعها ان نؤسس لنظامسيلسي دائم ومستقر، ووصفت المادة الاولى من الدستور هذا النظام بأنه "نظام اشتز اكي ديمقر اطي لنطي يقوم على تحالف قوى الشعب العاملة، و اعتبرت الشعب المصري الذي يتحدث هذا النظام بلسمه "جزءا من الامة العربية يعهل على تحقيق وحدنها"، وربما عبر هذا التوصيف بدقة عن مرحلة ما قبل حرب نشرين الاول/ اكتوبر 
س 19V، حيث كانت سلطة السادات ما تز ال هثة، اما بعد هذه الحرب فقد

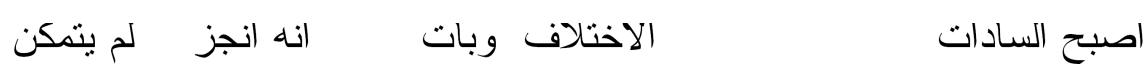
الرئيس عبد الناصر من تحقيقه ومن تم فمن حقه، ان يؤسس لمرحلة جديدة يصنعها هو بفسه، و هكدا راح السادات ينتهجةسيلسة خارجية وداخلية مختلفة

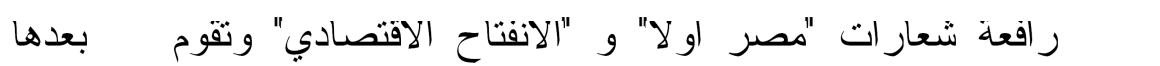

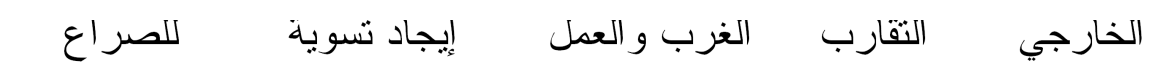
"إسر ائيل"، وتحاول في بعدها الداخلي إرساء دعائم لفلسفةسيلسة تتموية مختلفة

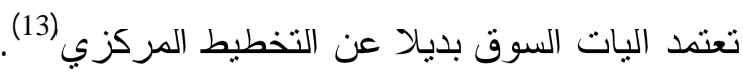
لقد اعتقد السادات ان بوسعه ان يمضي قدما فيسيلساته الجديدة دون ما لماتيط حلجة إلى اي تغيير في بنية النظام السياسي، او حتق في نصوص دسنور

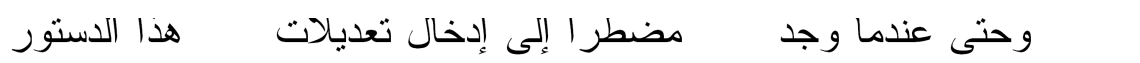
عام · 191، لم يكن الهدف من هذه التعديلات تغيير البنية السياسية لنظام الحكم ولكن لإحكام قبضته وسيطرنه الشخصية على نظام بدا غير قادر على الضبط النتلائي للإِيقاع السريع لحركة النغير الاجتماعي الني اطلقها. على صعيد اخر يلاحظ ان دستور $19 V 1$ و الذي اعتمد في صيغته الاصلية نظام الحزب الو احد،

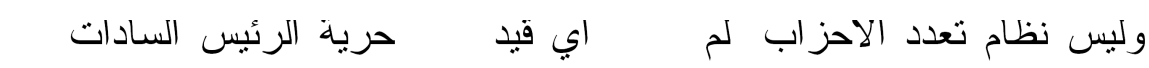

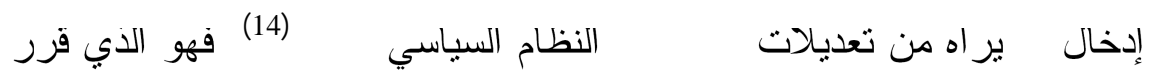
بعد حرب س19VF الانتقال من صيغة الحزب الواحد إلى صيغة المنابر المتعددة داخل نفس الحزب، وهو ايضا فرر الانتقال من تجربة المنابر المتعددة داخل

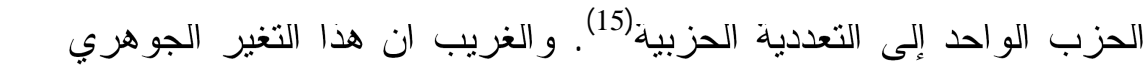
طبيعة النظام نم دون ما حلجة لتعديل مسبق في الدستور !. 
وقد حرص السادات، في بداية التجربة الحزبية، ان يناى بفسه بعيدا عن

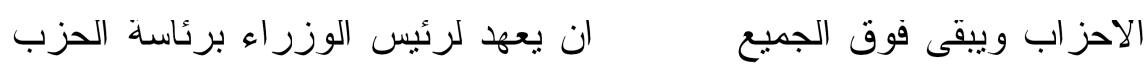

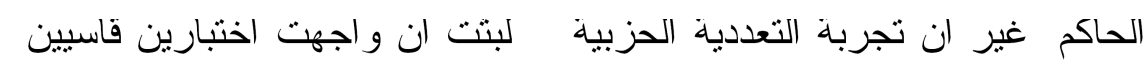
الاول: بمنلبة اندلاع انتقاضة الخبز يومي (IN IV) كانون الثاني/ يناير I9VV بسبب التقلصات الاجنماعية الني احدتها "الانفتاح الاقتصادي"

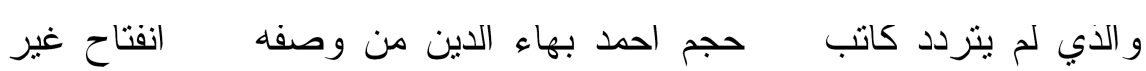
مجدي و الثناني: بمنلسبة المعارضة الشعبية الو اسعة لمعاهدة السلام المنفردة مع "إسر ائيل" والتي ادت إلى عزلة مصر عن عالمها العربي، وتقلص دورها ووزنها الإقليمي. وفي زخم النشاط الحزبي الواسع المعارض لهذه السياسات، اصدر السادات مجموعة القوانين الني عرفت باسم القوانين "سيئة الصيت"،

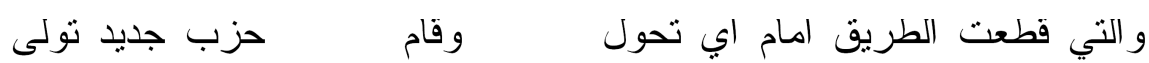
رئاسته بفهس وونذ ذلك الثاريخ اختلطت الامور وتاهت الحدود بين رئاسة الدولة ورئاسة الحزب، وتحول الحزب الحاكم في واقع الامر إلى اتحاد اشتر اكي جديد اسمه "الحزب الوطني الديمقر اطي"، و هكذا تحول النظام السياسي وني المصري شكلا، من نظام يقوده حزب و احد إلى نظام منعدد الاحز اب، إلا انه اصبح من الناحية الفعلية نظاما مغلقا على نهسه بالكلمل، وهذه هي خصائص النظام الذي ورنه الرئيس محمد حسني مبارك، الذي نسلم نظام حكم شديد الفردية، ومجتمع في حالة احتقان. و اختار مبارك ان ييقي على بنية النظام

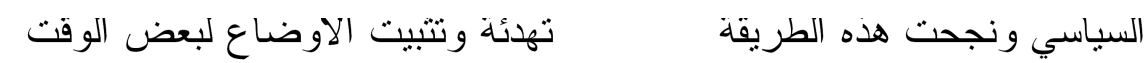
فالنظام يعكس هيمنة راس المال على الحكم باكثر مما يعكس تحالف قوى الشعب العاملة، اما تركيز السلطة في يد شخص و احد (16). 
كانت المادة (VV) من الدستور الحالي تحظر ترشيح نفس الشخص لاكتر

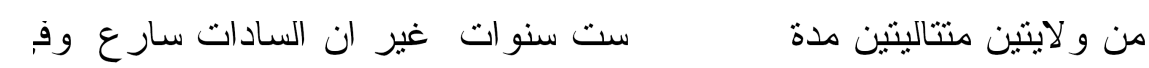
اول ازمة حادة يو اجهـام نظام حكمه، بتعديل هذه المادة ومن المفارقات ان الرجل الذي عدل هذا النص لم يكن هو المستقبد منه (17). وللإنصاف فقد نز اجع مطلب تعديل بنية النظام السياسي في بداية حكم مبارك، بسبب الظروف الماساوية الني جرى فيها اغتيال السادات، في وقت لم

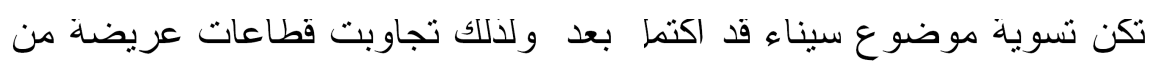
الشعب مع اولويات النظام في اسنكمال تحريز سيناء و الجهود الر امية لإصلاح الاقتصاد، واستعادة دور مصر العربي، و غيرها من الاولويات، خصوصا وان

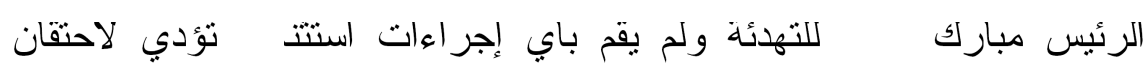
الساحة السياسية، مما ساعد على تحقيق إنجاز ات و اضحة في البداية، غير انه بمرور الوقت، ومع استمر ار بقاء نفس القبادات في مو اقعها لفتر ات طويلة بدات تظهر اعر اض لمظاهر فسادسيلسي و اقتصادي كبير، وبدا شعور قطاعات

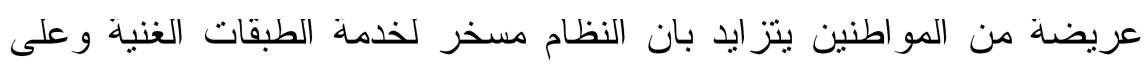

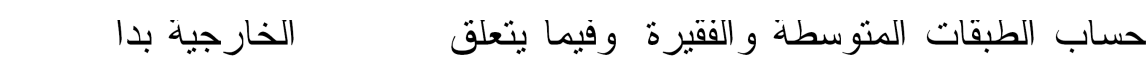
تدريجيا ان عودة مصر للصف العربي لم تساعد على تحصين المنطقة ضد الاخطار الني تتهدها، وان اوضاع الامن في المنطقة ككل بما فيها الامن

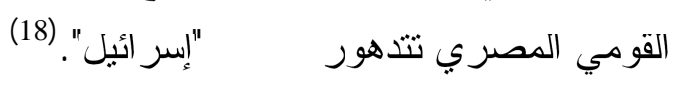

وبقدر تعلق الامر بصلاحيات رئيس الجمهورية طبقا لنصوص الدستور ندكر ا: رئيس السلطة التنفيذية.. . يضع بالاشتر اك مع مجلس الوزر اء السياسة

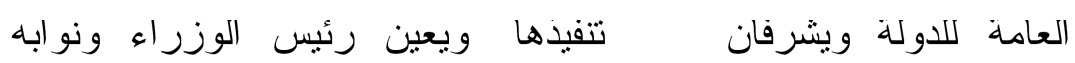
و الوزر اء ونو ابهم ويعفيهم من مناصبهم، وله حق دعوة مجلس الوزر اء 
للانعقاد وحضور جلساته ورئاستها وله حق طلب تقارير من الوزر اء.

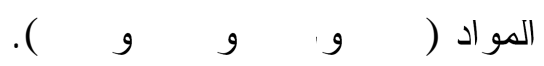

يعين الموظفين المدنبين و العسكريين و الممتلين السياسيين ويعزلهم،المادة وعران

يصدر اللوائح لنتفبذ القوانين ولوائح الضبط، و القرارات اللازمة لإنشاء

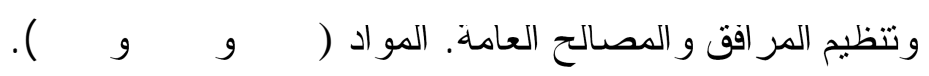

له حق إصدار قرارات لها قوة القانون في غيبة مجلس الشعب، ويعلن حالة الطوارىء،وله حق العفو عن العقوبة وتخفيفها، وله ان يستثف هوب الشعب من المسائل الهامة. المو اد (147) (184) (1492) (152). ولرئيس الجمهورية طبقا للمادة (IVE) الثهيرة" إذ قام خطر بهـد الوحدة الوطنية او سلامة الوطن او يعوق مؤسسات الدولة عن اداء دورها الاستوري، ان بتخذ الإجراءات السريعة لمو اجهة هذا الخطر ويوجه بيانا إلى الشعب، ويجري الاستقتاء على ما إنخده من إجراءات خلال ستين

$$
\text { يوما من إنخاذها (19). }
$$

يسجل فقهاء القانون الدسنوري ان الدستور لم يوضح الحدود الفاصلة بين دور رئيس الجمهورية ومجلس الوزر اء في اتخاذ القرار، و المسئولية البرلمانية تتحصر في مجلس الوزر اء وحده، بمعنى ان ما بتخذه رئيس الجمهورية من ون قر ار ات وما برسمه من سياسات، إنما يكون بعيدا عن رقابة سائر السلطات في الدولة وقد وصف (محمد حسين عبد العال) هذه المادة في كتابه "القانون الدستوري" قائلا: " من الواضح ان الحكم الذي تتضمنه هذه المادة بالغ الاهمية

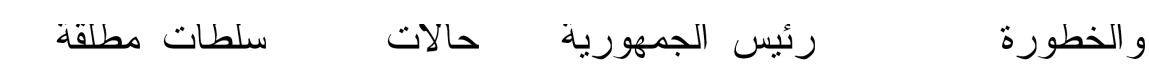
تخضع لاي قبد. ولم تتضمن الدساتير المصرية السابقة على النورة او اللاحقة 
لها اي حكم ممانل لذلك الذي ثقرره المادة (1V) من دستور I IVV) (20) في مقالبل هذه السلطات كلها فالرئيس المصري ليس مسؤو لا امام ممثلي الشعب، وفوق هذا كله فرض قانون الطوارئ الذي بعطي لسلطات الدولة سلطات و اسعة تحدَ كثير ا من الحقوق المدنية للمو اطنين المصريين. (21) وفيما يخص مجلس الشعب الذي يبلغ عدد اعضائه (ععع) و عشرة اعضاء وله سلطات تشريعية كما يمارس الرقابة على السلطة التنفبذية الا ان مايعمق ازمة ولهة السلطة التشريعية سبطرة الحزب الحاكم على المجلس من خلل الاغلبية(22).

\section{2_ التغيرات التي شهدتها مصر بهرف الإصلاح السياسي:}

شهرت مصر خلال السنوات الاخيرة حراكا رسمبا نشطا هدفه الاصلاح على كلفة الاصعدة ولكن وفق مايضمن نطبيق الاستر اتيجية الحكومبة في ادارة البلاد، وفي نفس الوقت امتصاص الحراك الشُعبي الذي بطالب باصلاحسيلسي هقيقي بمدياته المقبولة،وفي هذا السباق صمم مشروع الحزب الحاكم للإصدلاح متضمنا مر احل تلاث؛.الاولى تبدا بتعديل مادة وحيدة في الدسنور هي المادة (V7) لضمان حصول الرئيس اولا علي و لاية سادسة بوسيلة اخرى غير وسيلة الاستفتاء، و التنانية تتمل في إجر اء انتخابات تشريعة بطريقة يمكن ان تسفر عن سيطرة الحزب الحاكم علي مالايقل عن ثلثي مقاعد مجلس الشعب، و التالتة إجر اء تعديلات و اسعة النطاق على الدستور من الممكن

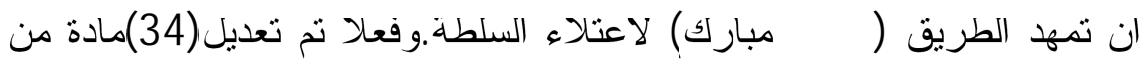
الدستور (23)

\section{إـإلتعديلات الدستوريه التي شهذتها مصرفي الاونه الاخيرة:}

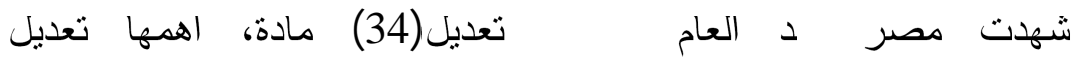
المادة(V7)من الدستور، الخاصة بشروط ونظام انتخاب رئبس الجمهورية، 
و على الرغم من إن هذا التعديل وضع شروط صعبة للترشيح و امد و لاية

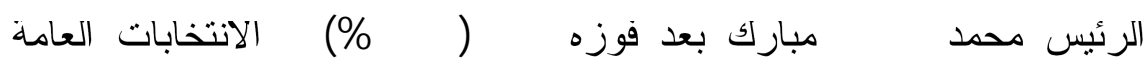

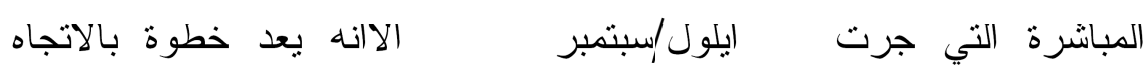
الصحيح، خاصة ان غالبية النُعب لم تشارك في الانتخابات.

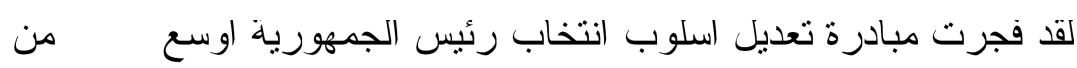
النقاش السياسي في مصر استمر لعدة شهور، وو اكب جمبع المر احل السياسية و الدستورية لتحويل هذه المبادرة إلى و اقع من خلل الجدل السياسي الشعبي، ثن

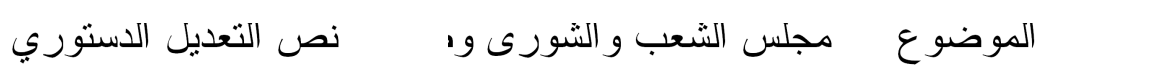

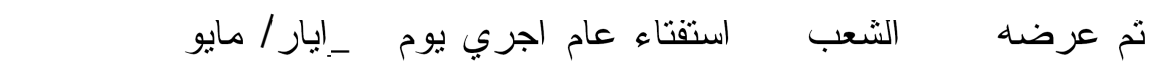
إطار من الالتز ام الكامل بالمر احل و الخطوات و المهل الني حددها الدستور .. وبعد مو افقة اغلبية المستقتنن على هذا التعديل اصبح ساريا اعتبار ا من إصداره

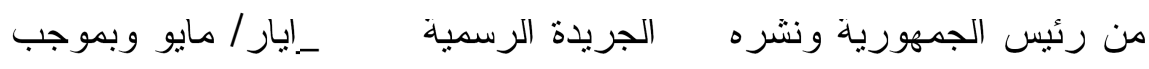
هذه التعديلات الدستورية فإن انتخاب رئيس الجمهورية ينم وفق مجمو عة جديدة

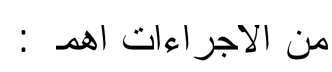

ـ ان رئيس الجمهورية ينتخب عن طريق الاقتز اع السري العام المباشر.

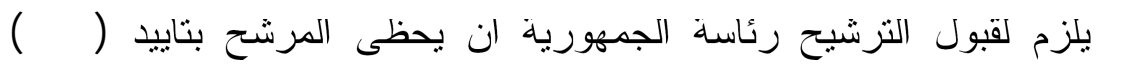

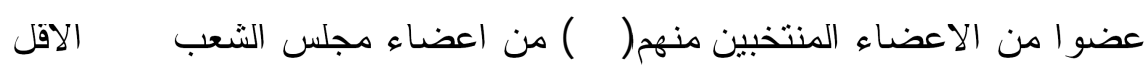

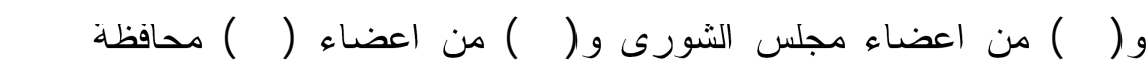

ـ للاحز اب السياسية الني مضي علي تلأسيسها اكتر من خطسة اعو ام متصلة وحصلت في اخر انتخابات برلمانية على (0\%) علي الاقل من مقاعد مجلسي الشعب و الشورى ان نرشح لرئاسة الجمهورية احد اعضاء هيئتها العليا بباسنتناء 


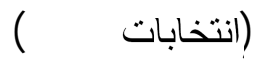

- تشكل لجنة الانتخابات الرئاسية لإِشر اف علي النرشيح وإجراءات الانتخابات و الاقتر اع و إعلان النتيجة وتكون هذه اللجنة برئاسة رئبس المحكمة الدسنورية العليا، و عضوية رئيس محكمة استئناف القاهرة، و اقدم نو اب رئيس المحكمة اللستورية العليا و اقدم نو اب رئيس محكمة النقض و اقدم نو اب رئيس مجلس الدولة وخمسة من الشخصبات العامة المشهود لها بالحباد. ولتطبيق التعديل الدستوري كان لابد من تشريع قو انين بهذا الصدد فصدر

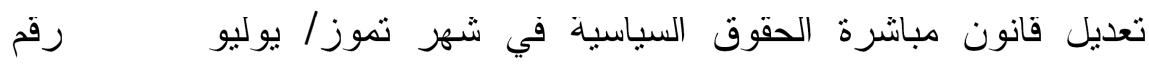

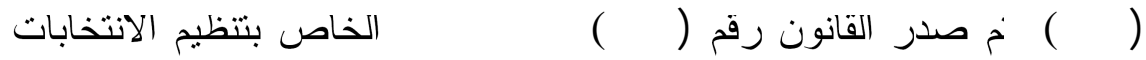
الرئاسية، وتضمن هذا القانون الإجر اءات التقصيلية الخاصة بعملية الانتخابات الرئاسية و الدعاية الانتخابية و غير ها. و استكمالا لما شهدته مصر من إصلاحات

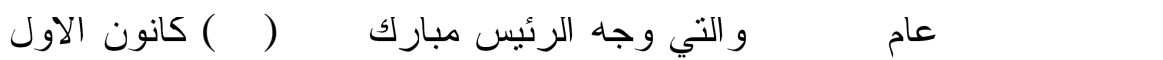

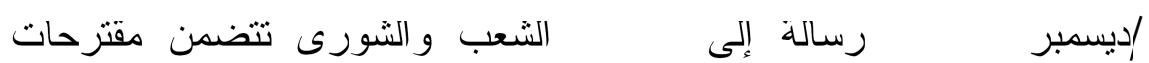
بإجر اء تعديلات دستورية، شملت (عَ) مادة من الاستور ، و على مدار شُهرين

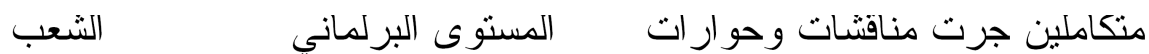
و الثورى، إضافة إلى المناقتات المجتمعية لشخصياتسيلسية، وقانونية، وقد

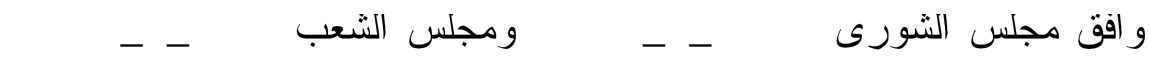

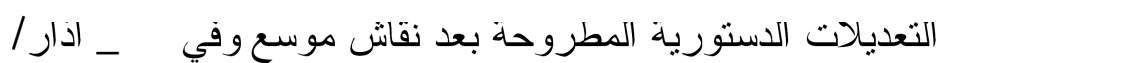
مارس V V.r. اجرى الاستفتاء على التعديلات المطروحة. وفد اعلنت نتيجة

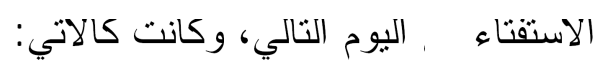
ـ عدد الناخبين المدعوين للاستفتاء (1\%) مليونا و (170) الفا و (770) 
ـ عدد الذين ادلو ا باصو اتهم في الاستقتاء على النعديلات الدستورية (9 ملايين

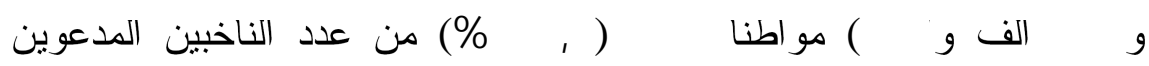
للاستقتاء. ـ عدد الاصوات الصحيحة بلغ (9 ملايين و وعع الفا وع IV) صوتا بنسبة

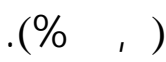
ـ عدد الاصوات الباطلة (ror) الفا و (790) صوتا بنسبة (T,\%).

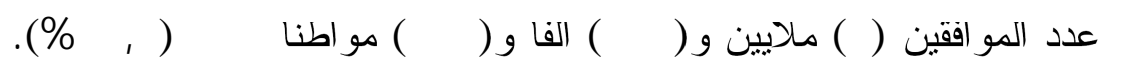
وقد اصبحت هذه النعديلات سارية بالفعل بعد تصديق رئيس الجمهورية في

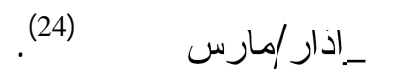
بعد إجر اء مزيد من التعدبل للمادة (V7) من الدستور بمثابة اعتر اف من

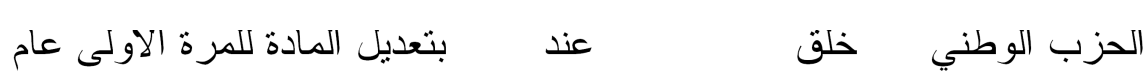
0

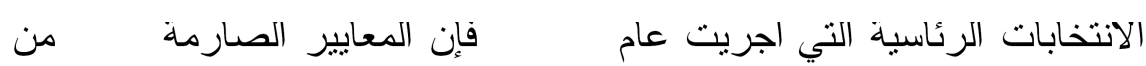

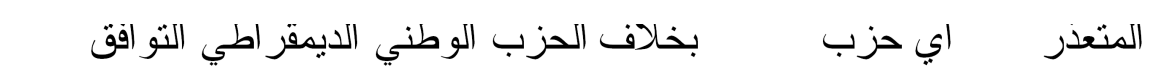
في الانتخابات القادمة عام I| · r. وكان الحزب الوطني قد وضع هذه المعايير لرغبته في إقصاء مرشحي الإخوان المسلمين، وليس خوفا من ابي منافسة

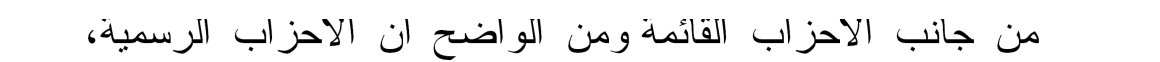
الوفد و التجمع و الناصري، تكمن مصلحتها في تاييد تعديل يسمح لها بالمشاركة بمرشحين في الانتخابات الرئاسية، وفي الوقت ذاته يستثي المنافسين غير المعتزف بهم قانونيا امنال الإخوان المسلمين وحزب الوسط (دي النوجها الإسلامي) وحزب الكرامة (ذي النوجهات الناصرية الجديدة) و الجبهة وهية الديمقر اطبة (تتع مسار اليبر البا)، و المادة (V7) المعدلة ثانيا تضغع شروطا ايسر 
امام الإخوان المسلمين، إذ لهم عدد من الخبار ات: إما إقامة حزب خاص بهم او تشكل تحالف مع حزب قائم او محاولة المشاركة في الانتخابات عبر مرشح

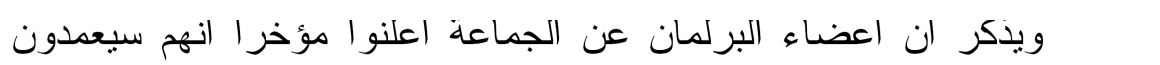
لاختبار النظام الحالي من خلال السعي لإقلمة حزب، الامر الذي من المحنمل

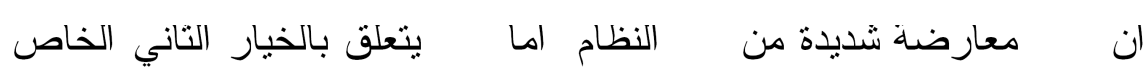
بتشكل تحالف مع حزب قائم (الامر الذي فعله الإخو ان بالفعل مرنين من قبل مع حزبي الوفد تم العمل خلال ثمانينيات القرن الماضي) فهو ممكن رغم صعو بته (25).

\section{ب:الاتتخابات الرئاسية و التشريعيه:}

لقد شهدت مصر و لاول مرة انتخابات على منصب رئيس الجمهورية وقد عدت ققلة على الرغم من السلبيات الني رافتتها،اذ تتافس فيها عشرة مرشحين

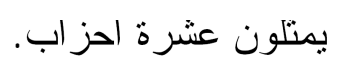

و اسفرت الانتخابات عن النتائج النالية:

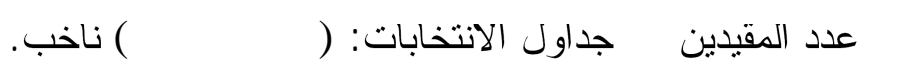

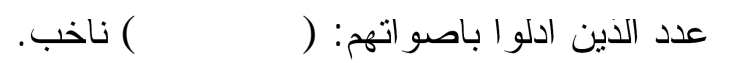

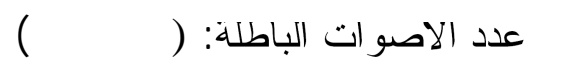

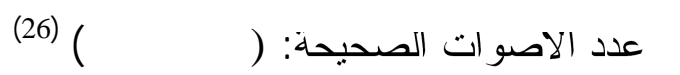
ـ نتيجة المرشحين: 1 ـ محمد هسني مبارك (الحزب الوطني الديمقر اطي) رمز الهلال ـ عدد

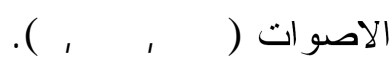


r ـ د.ايمن عبدالعزيز نور (حزب الغد)رمز النخلة- عدد الاصوات

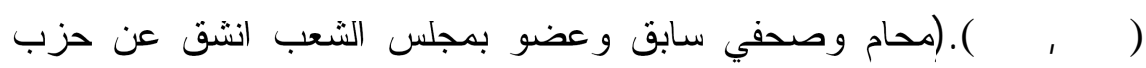

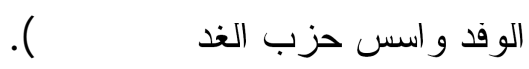

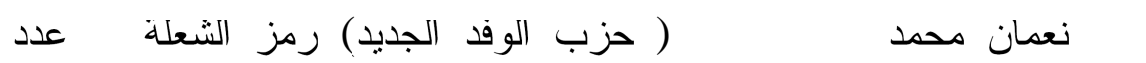

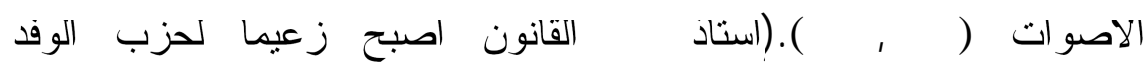

سنة . . (r).

ع - اسامة محمد عبدالثافي شلتوت( حزب التكافل) رمز الهرم - عدد الاصو ات (Yq,^OV).(عضو بمجلس الثورى و استاذ بكلية التجارة في جلمعة القاهرة وضابط سابق في البجيش).

0 - وحبد فخري الاقصرى( حزب مصر العربي الاشتر اكي) رمز الشمس عدد الاصو ات (199V1,111).(1) منصب الامبن العام لحزبه و اسس اللجنة المصرية لتوحبد الامة العربية عام1991) (199).

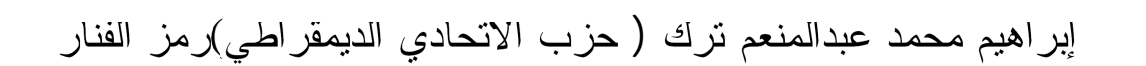

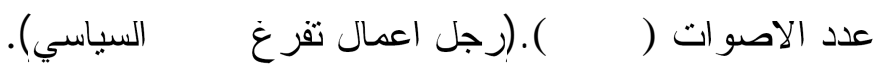

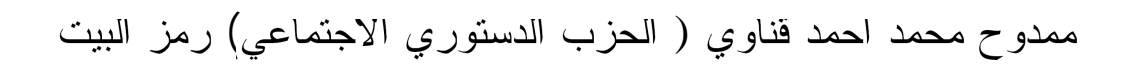

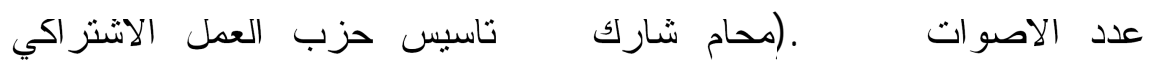

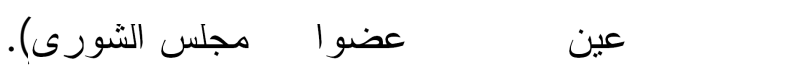

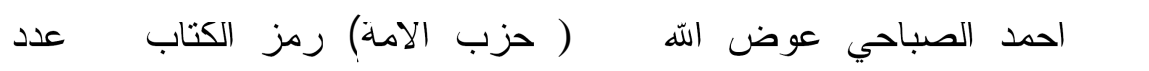
الاصوات (بوسع).(عضو مجلس الشورى منذ سنة1910 بشتهر بتقسير الاحلام) 9 ـ د/ فوزي خليل محمد غز ال ( حزب مصر . . . ) رمز السنبلة ـ عدد 
الاصو ات (r ع ع (استاذ في الرياضيات انخرط في العمل السياسيسنة ...

بعد تاسبس حزب مصر ).

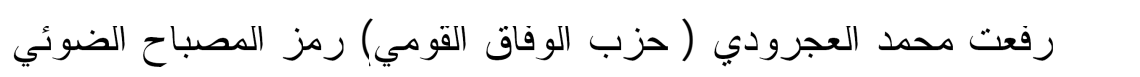

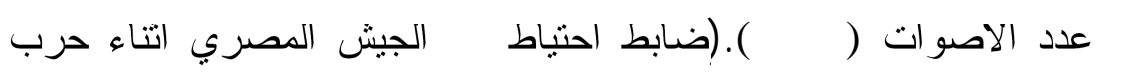

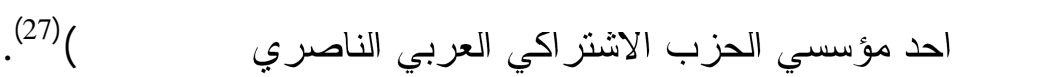

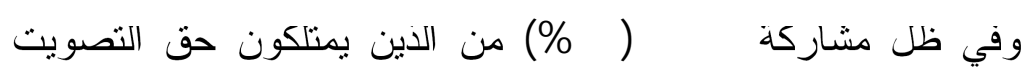

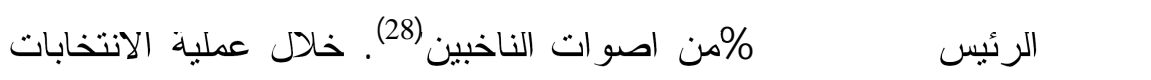

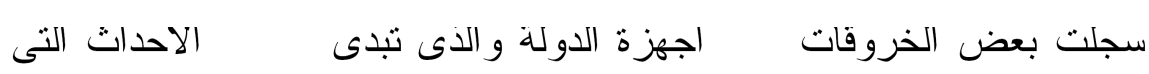

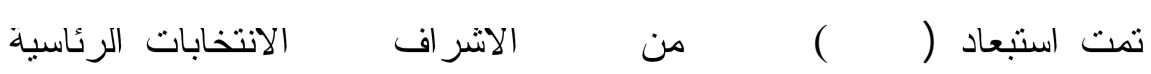

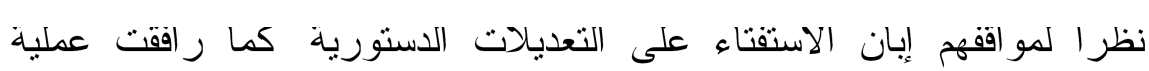

$$
\text { الانتخابات العديد من السلبيات نذكر منها: }
$$

I. القاء القبض على عدد من مرشحي المعارضة فضلا عن عن انتبالكات بين

$$
\text { منظاهرين ادت الى مصر ع عشرة منهم (29). }
$$

r. اعتماد محامو الحكومة|عضاء هيئة قضايا الدولة و اعضاء النياءة النية الادارية،

$$
\text { كمشرفين على اللجان الانتخابية. }
$$

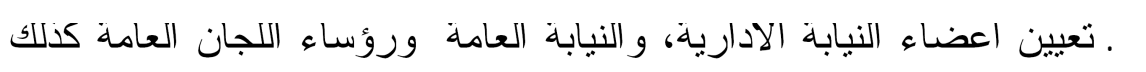

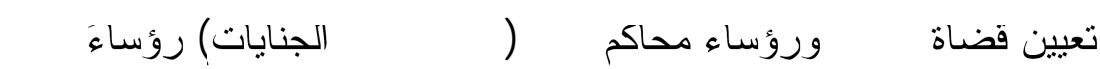

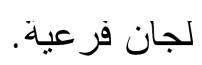

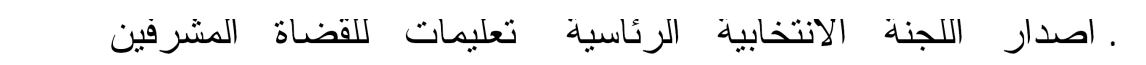

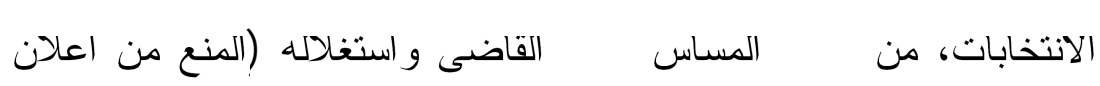

$$
\text { نتيجة فرز الاصو ات داخل اللجنة). }
$$

0. تاييدشيخ الازهر لمرشح الحزب الوطني. 
7 ـ استخدام الو ازع الدينى من قبل القبادات الرسمية الاسلامية و المسيحية لدفع

$$
\text { المو اطنين للتصويت لصالح مرشح الحزب الوطني(30). }
$$

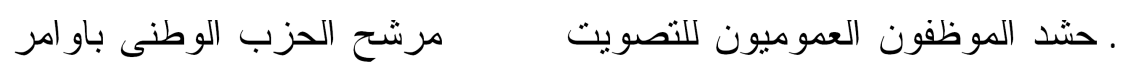

من رؤسائهم الاداريين،فضلا عن الحبر الفسفوري الرديء مما يمكن محوه

$$
\text { بسهولة }
$$

1. استخدام وسائل النقل و المو اصلات المملوكة لهيئات ومصالح حكومية فى تقل العمال و الموظفين الذين تم حشدهم الى حيث المقار الانتخابية و التاكيد

$$
\text { عليهم بالنصويت لصالح مرشّح الحزب الوطنى (31). }
$$

وفيما يخص الانتخابات النشريعية فقد ارخت هذه الانتخابات لمرحلة جديدة

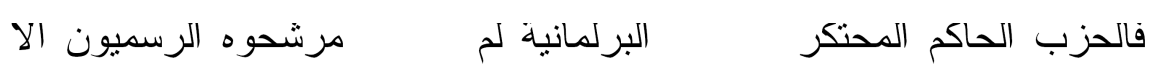
على (0، بر \%) من مقاعد البرلمان بينما حصل مرشحو الاخوان المسلمين على حوالي (·r\%) مع ملاحظة ان الحزب الوطني خاض الانتخابات

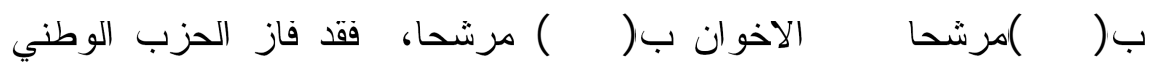

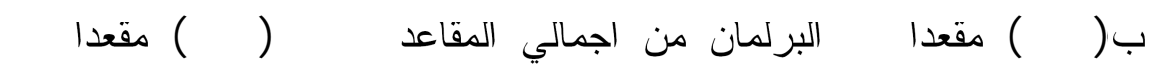

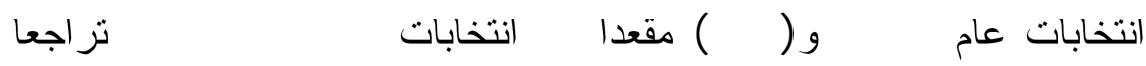
ملحوظا لثعبية الحزب رغم استمر ار احتكاره للسلطة وبالمقابل فاز الاخوان

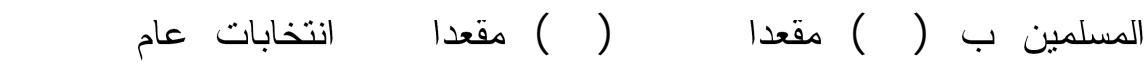
(12)ومقعدا في انتخابات عام 1984مما يعني ان الجماعة ضاعفت تمثليها

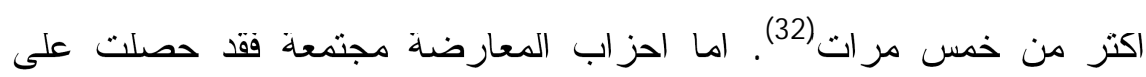

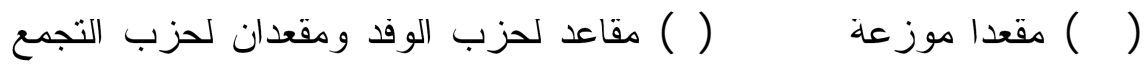
ومقعدان لحزب الغد ومقعدان لحزب الكرامة ومقعد لحزب الاحرار واخر للتجمع الوطني للاصلاح الديموقراطي وحصل مستقلون على (19) مقعدا 
وبذلك اختقت باقي الاحز اب عن مجلس الثُعب. ويمكن رصد بعض الظو اهر المهمة التي رافقت الانتخابات:

- ظاهرة المنشقين على الحزب الوطني في الانتخابات المنظمين البه بعد

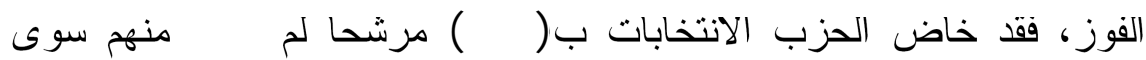
(1ع0) وبالمقابل فقد وصل عدد المنشقين على الحزب حوالي الالفين فاز

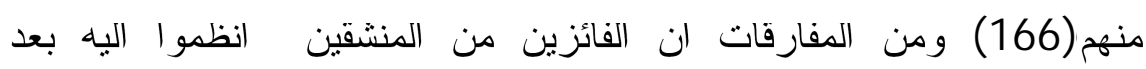
الانتخابات فشكلو ا الاغلبية في المجلس.

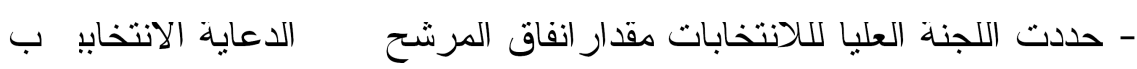
الف جنيه الا ان انفاق بعض المرشحين وصل الى خمسة ملايين جنيه (V.) وقدرت بعض المصادر الانفاق الكلي ب( 0) مليار ات جنيه مما يجعل هذه الانتخاتبات الاغلى في ناريخ مصر (33). وقد اصدرت المنظمة المصرية لحقوق الإنسان في عا_r

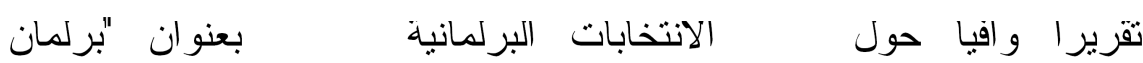

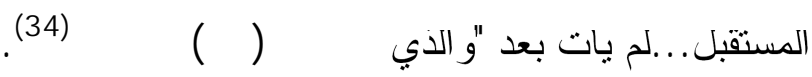

3 -مظاهر الاصلاح و التغيير:

من المظاهر المههة الني تلفت الانتباه، حصول جماعة الإخوان المسلمين

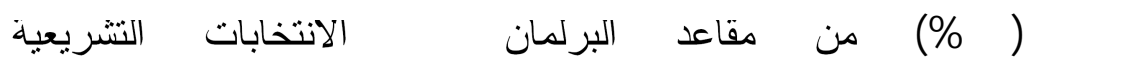

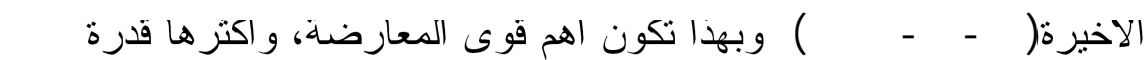
منافسة الحزب الحاكم،على الرغم من عدم السماح لها بالعمل كحزب مجاز (35)،

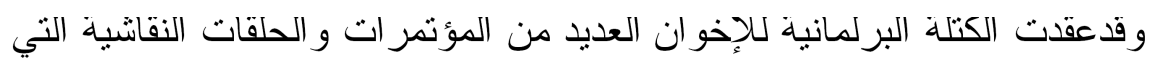
تبين موقفها من القضايا الجوهرية الني تتار داخل اروقة مجلس الشّب، و على لئ راسها موققها من مسألة النعديلات الدسنورية، وما برنبط بها من قضايا مكملة؛ 
مل قانون إحالة المدنبين إلى القضاء العسكري، وغبرها من القضايا المهمة ذات الصلة، وذلك بمشاركة العديد من احزاب المعارضة و القوى المصرية

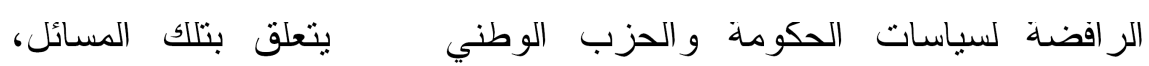
و اصدرت الكتلة ورقة تبين رؤيتهم للتعديلات، و اقتر احاتهم للصياغة المفترضة للتعديلات وعقدت مؤتمرًا صحفيّا يوم r.J_Ir_rV لبيان موقفهم من

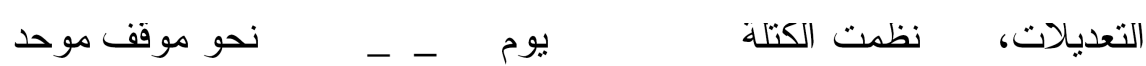
للمعارضة، عن موقفهم النهائي من النعديلات الدستورية(36)، كما عقدت الكتلة اجتماعًا تتسيقيًا مع احزاب المعارضة لرفض التعديلات بمقر المجلس في

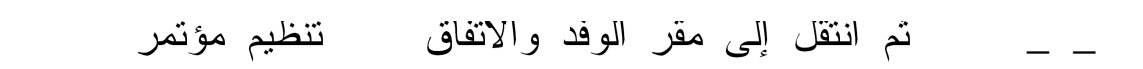

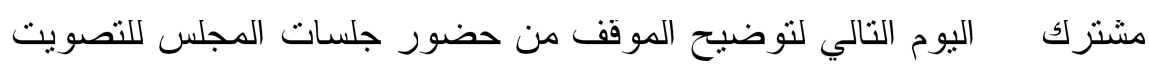

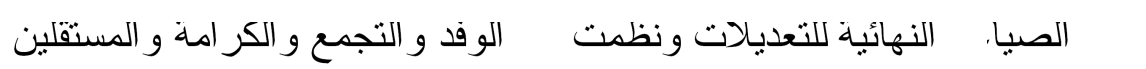

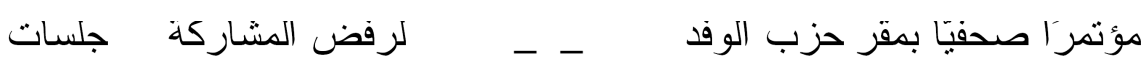
النصويت على النعديلات، و الانسحاب من الجلسة المخصصة لمناقثة النعديلات احتجاجًا على منعهم من المشاركة في لجنة الصباغة،واصدرت ولفي الكتلة بيانا برفض النعديلات يوم 1 الكر امة و اتتان من نواب حزب الوفد كان بمثابة إبر اء الذمة من التعديلات الدستورية و اعتصام (r · ( نائب) ثلاثة ايام بمقر المجلس، ارتدى خلالها

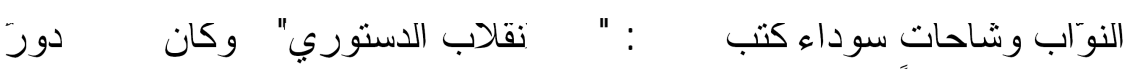

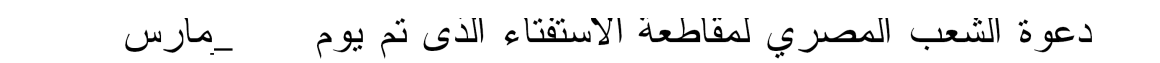

كذلك برزت فوى مطالبة بالإصلاح كحركه" كفاية" الني ظهرت صيف

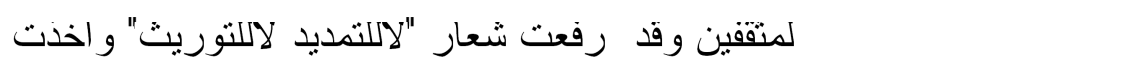


تكسب ارضية جيدة على الساحة السياسية المصرية(38)، كذلك "الجبهة الشعبية لإنقاذ مصر"، فضلا عن شخصيات علمة تطالب بالتغيير، مما يعطي مؤشرا

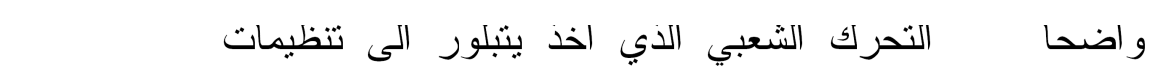

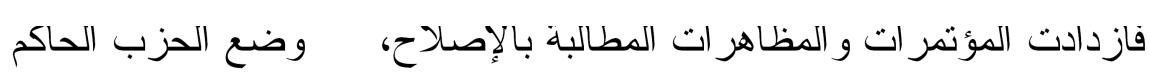
في موقف اضعف من ذي قل، فلم تسنطع الحكومة استخدام قانون الطوارئ

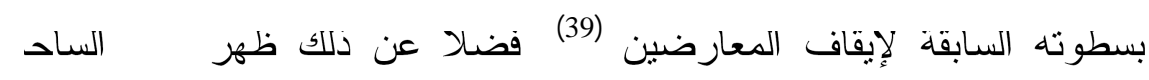

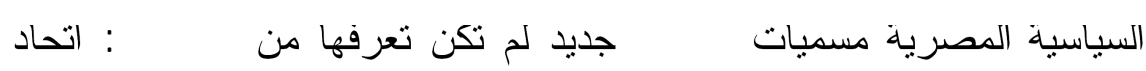

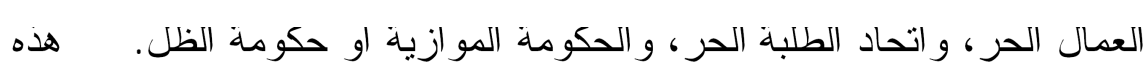

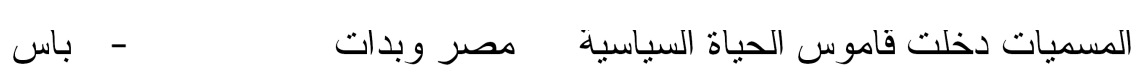

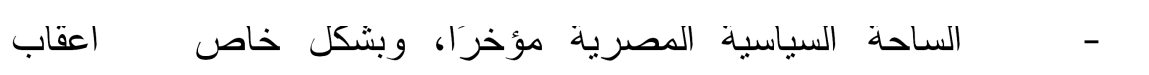

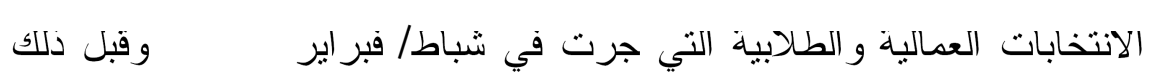
عقب الانتخابات البرلمانية (40). لايمكن اغفال دور القضاء المصري الذي اخذ بظهر على الساحة

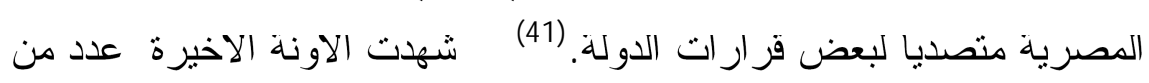
المؤتمر ات و الندوات التي نتاولت مسألة الاصلاح في مصر مسجلة ظاهرة صحية نذكر منها الندوة الني اقامها (مركز الحوار العربي) في و انتطن حول

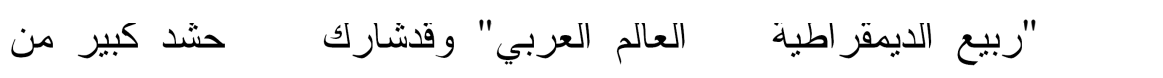

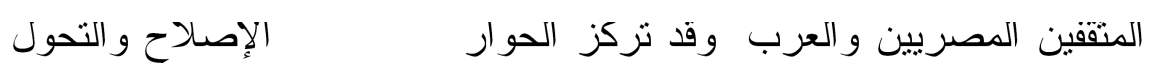
نحو الديمقر اطبة في مصر باعتبار ها اكبر الدول العربية، ومن هؤلاء المتقفين

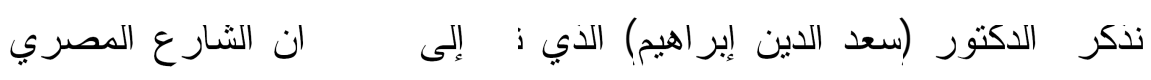
يظهر قدرته الفائقة على المشاركة بصوته وبنسب تزيد عن (VO) في المائة عندما تتوفر الفرص الحقيقية في المنافسة ويظهر ذلك واضحا في انتخابات 
النقابات بل ومجالس إدارات النوادي الرياضية حيث يدرك ما تتمتع به ثلك الانتخابات من مصداقية وما يتوفر فيها من نتافس حقيقي وشفافية في عمليات

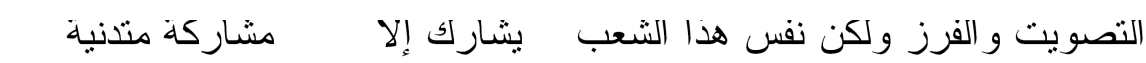
الاستقتاءات التي كانت تجرى (42).

وفي فعاليات اليوم الاول للملقفى الفكري العاثر (للمنظمة المصرية لحقوق

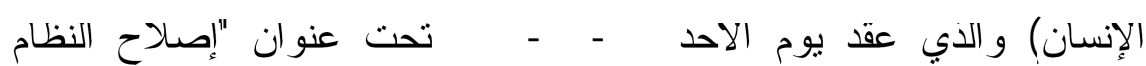
الانتخابي في مصر ...الضرورات و الاليات ".اكد الاستاذ (حافظ ابو سعده) الامين العام للمنظمة المصرية في كلمته الافتتاحية ان انعقاد الملتقى الفكري

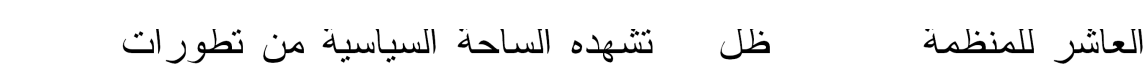
بعملية الإصلاح السياسي و الدستوري،ونز ايد ضغوط في القوى السياسية و الحزبية و المجتمعية، وباعتبار الإصلاح الانتخابي بصفة علمة و إصلاح النظام الانتخابي بصفة خاصة ركيزة اساسية من ركائز الإصلاح السياسي و الدستوري وقت فالحرية لها تمن، فهي لا تمنح و إنما نتنز ع (43). ومن مظاهر الاصلاح الجديدة على الساحة السياسية المصرية ظهور شخصبات لها بعض النقل ولو الإعلامي رغم النضبيق من قبل السلطة المصرية:فعلى سبيل المتال فان المعارض "ايمن نور" اصبح ظاهرة مثبرة للجدل في كثير من الاوساط المصرية الان، فقد استطاع خلال فترة وجيزة من

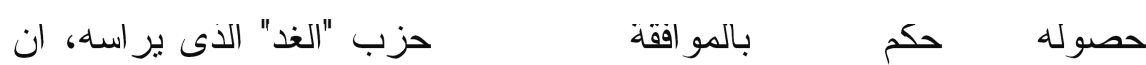
يكون واحدا من الارقام المنداولة في قضية الإصلاح (44). 4 - رؤى الاصلاح بين الحزب الحاكم والمعارضه: ا.-رؤية الحزب الوطني لمسيرة الإصداح السياسي: 
يؤكد الحزب الوطني الديمقر اطي على التز امه مسيرةالاصلاح، من خلل

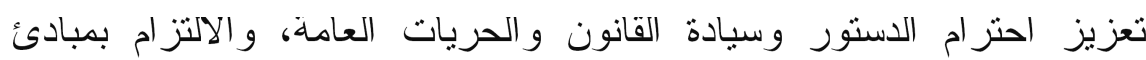
الثفافية و المساءلة في العمل العام وحرية الصحافة و الإعلام، وتشجيع المشاركة السياسية بأثكالها ومسنوياتها المختلفة، وقد تضمنت ورقة" حقوق المو اطنة

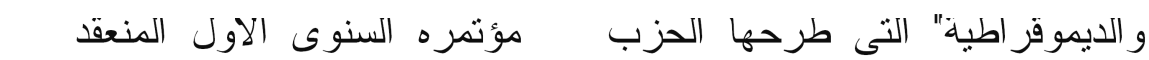
ابلول/سبتمبر سب. . r رؤية الحزب و اهدافه فيما بتعلق بمسيرة الإصلاح السياسى، وقد اكد الحزب فى هذه الورقة على التزابط الوثيق بين مجالات

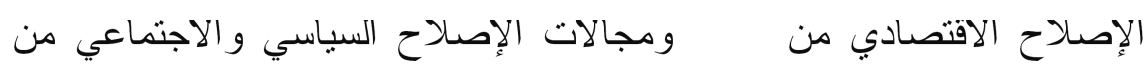

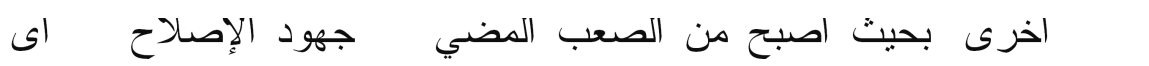
منهما بمعزل عن الاخر ـ وقد وطرحت ورقة حقوق المو اطنة و الديمقر اطية عدة اهداف تمل رؤية الحزب لتحقيق عملية الإصلاح السياسي و المؤسسي و الثقافي و تتمثل في إنشاء المجلس القومى لحقوق الإنسان، إلغاء محاكم امن الدولة العليا

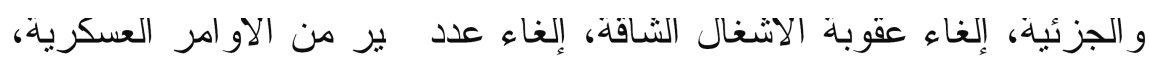
إصدار قانون إنشاء محاكم الاسرة وصندوق النفقة، تعديل قانون الجنسية و الذى ساوى بين من يولد لاب مصري و ام مصرية فى التمتع بالجنسية المصرية(45).

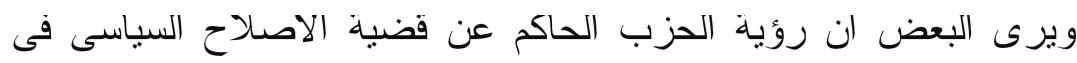
مصر جاءت محبطة ومخيبة للامل، كذلك فيها فجوة بين الاعلان و التطبيق على ارض الو اقع (46).

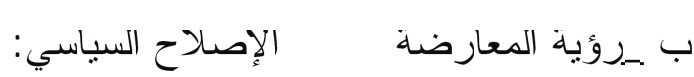

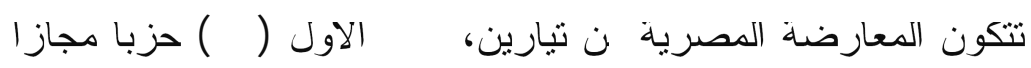
ضمن القانون، اغلبها احزاب صغيرة لبس لها دور سيلسي و اضح او قاعدة شعبية،و لا نغالي إن وصفناها بللثكلية، ويكفي ان نعرف ان جمبع احزاب 
المعارضة حصلت في الانتخابات النشريعية الاخيرة عله(\%\%) من مقاعد

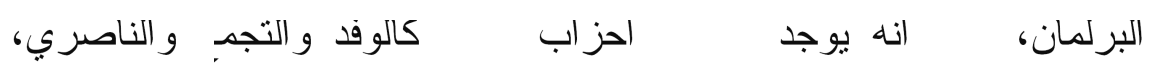

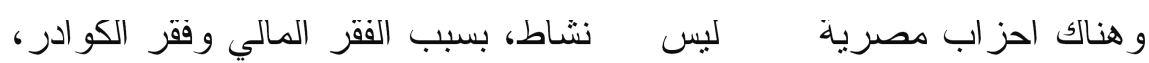
و اخرى نشطة ولكنها مجمدة وتمارس عملها عبر الإنترنت، وهناك نبار ات

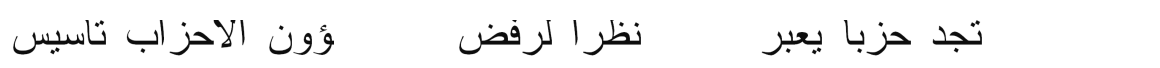
احز اب جديدة لها و عدم الرغبة الرسمية في الاعتر اف بها.

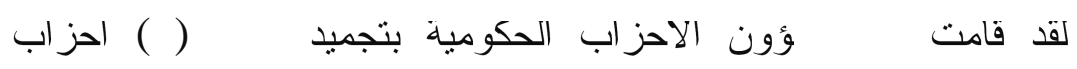

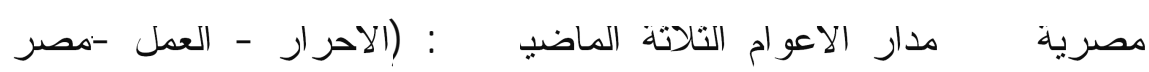

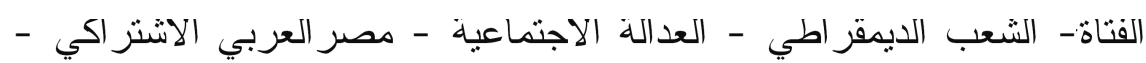
الوفاق القومي).وفي مقابل نجمبد الاحزاب السبعة عانت ققية الاحزاب من مزيد من التهمبش و النضبيق و المشّاكل المالية، فالاحز اب الكبرى مل لونيل الوفد

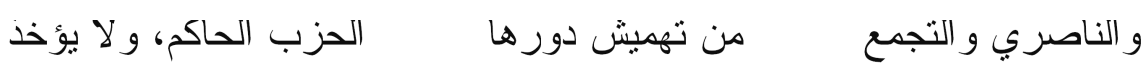

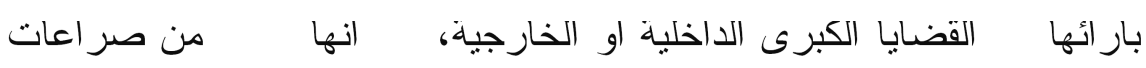
داخلية بين الجيل القديم و الجديد، و الاحز اب الصغرى تصارع فقط للحصول

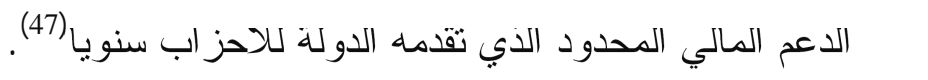
اما النتار التناني فينكون من عدة حركات وتجمعات اهمها جماعة الإخوان المسلمين، إضافة إلى حركات عدة داخل وخارج مصر، ويتمبز هذا النبار بوضوح الرؤيا و القو اعد الثُعبية.

تتفق نبار ات المعارضة على اختلاف توجهاتها على اغلب المبادئ العامة

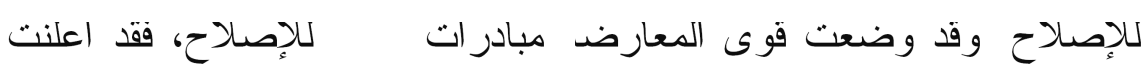
جماعة الإخوان المسلمين عن رؤيتها للإصداح فقد قدم المرشد العام للإخوان 


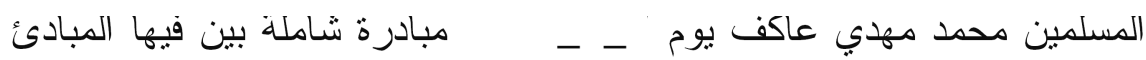
العامة للإصلاح من وجهة نظر الإخوان في مصر ويمكن اختصار بنودها فيما

1 -الإقر ار التام بان الشعب هو مصدر جميع السلطات،

2 - الالنز ام و احتر ام مبدا تداول السلطة، عبر الاقتز اع العام الحر النــزيه.

3 - تاكيد حرية الر اي والجهر به، و الدعوة السلمبة إليه في نطاق النظام العام

و الاداب العامة، ويعتبر حرية النملك و استعمال وسائل الإعلام المختلفة ضرورة لتحقيق ذلك.

4 - ناكيد حرية نشكيل الاحزاب السياسية، والا يكون لاية جهة إدارية حق التذخل بالمنع او الحد من هذا الحق، وان تكون السلطة القضائبة المستقلة هي المرجع لتقرير ما هو مخالف للنظام العام والاداب العامة. 5 - تاكيد حرية الاجنماعات الجماهبرية العامة، و الدعوة إلبه.

6 - تاكيد ضرورة تمثنيل الشعب عبر مجلس نبابي منتخب انتخابًا حرَّا، ولمدة محدودة، يُعاد بعدها الانتخاب.

7 - ضمان حق كل مو اطن ومو اطنة في المشاركة في الانتخابات النيابية. 8 - إبعاد الجيش عن السياسة، وان يكون وزير الدفاع مدنبًا سياسيّا كسائر

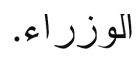
9 - تحديد سلطات رئيس الجمهورية، بما يجعله رمزًا لكل المصريين، فلا يتر اس اي حزب سياسي، ويكون بعيدًا كل البعد عن المسؤولية التنفيذية للحكم،

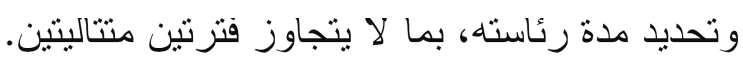


10 - إلغاء القوانين سيئة الصيت، و على الاخص قانون الطوارئ، وقانون

الاحزاب، وقانون المدعي العام الاشتر اكي، وقانون مباشرة الحقوق

السياسية، وقانون الصحافة، وقانون النقابات، وغير ها من القو انين.

11 - الإفراج عن المعتقلين السباسيين و القضاء على ظاهرة التعديب، و إعادة

النظر في الاحكام الصادرة من محاكم استنتائية عسكرية (48).

ـ حزب الوصد:

يرى حزب الوفد ان الدستور الذى وضع عام 1971 فى ظل سيادة نظرية

المجتمع الاشتر اكى - قد توسع فى سلطات و اختصاصات رئيس الجمهورية، و السلطة التنفيذية على حساب باقى المؤسسات الدستورية، ولذلك اصبحت البلاد كما يقول (محمود اباظة) نائب رئيس حزب الوفد فى حاجة إلى دستور جديد يصدر بار ادة شعبية حرة، ومن اهم المبادئ النى سيقوم عليها هذا الدستور، اختبار رئيس الجمهورية ونائبه، حيث برى حزب الوفد ان ينم اختبار رئيس الجمهورية بالانتخاب العام المباشر بين اكتر من مرشح من الاحزاب الممنتلة فى مجلس الشعب، ودلك لان هذا النظام الديمقراطى بحقق العديد من المزايا، حيث يتماشى مع منطق تعدد الاحز اب من ناحية، ومن ناحية اخرى ينهى هذا التعديل تحكم مجلس الشعب او حزب الغالبية فى اختيار المرشح الوحيد لرئاسة الدولة، كما يجعل ولاية رئيس الجمهورية مستمدة من الشُعب مباشرة دون سواه، وهو ما يتفق ومبدا سبادة الامة، كذلك يجب ان بيتولى نائب الرئيس منصبه بالانتخاب ايضا و إعادة النظر في ثوزيع السلطات بين رئبس الجمهورية و المؤسسات الدستورية الاخرى كما يجوز لاى حزب ان يقيم تنظبمات عسكرية 
او شبه عسكرية، او بلجا إلى التنظيم الحزبى فى صفوف القوات المسلحة و اجهزة الامن (49).

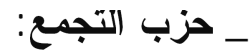

ويطرح حزب التجمع عدة نقاط رئيسة برى انها تعد المدخل السليم

للإصلاح السباسى وهى كما يقول (حسين عبد الرازف) الامين العام للحزب: ـ تعديل قانون مباشرة الحقوق السياسبة وقانون انتخابات مجلس الشعب لاجر اء انتخابات حرة نزيهة، على ان ثشرف عليها لجنة قضائية مستقلة ودائمة و غير قابلة للعزل، او لاى تذخل من السلطات التتفيذبة. _ يتولى القضاء الطبيعي وحده الفصل فى اية نز اعات حزبية. ـ تحرير النقابات و الجمعيات الاهلية ومؤسسات المجتمع المدنى من تدخل الجهات الإدارية، مع إلغاء القانون ( . . (1) الذى تسبب فى سقوط الكثير من النقابات فى مستتقع فرض الحر اسة علبها| (50).

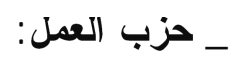

الاصلاح السباسي فى مفهوم حزب بتطلب سعبا جادا من كل المصريين شعبا وحكومة، و البداية نكون باعتر اف الجمبع بوجود خلال سياسبا وفسادا بجب "يج إصلاحها... ويرى حزب العمل في إلغاء القو انين سيئة السمعة التى تعطى للجنة إدارية حق وقف او إلغاء او تعطبل نشاط اى حزب من الاحز اب، ويتبع ذلك إطلاق حرية إصدار الصحف، و تغبير المناخ الفاسد الذى نعيشه إلى مناخ جمهورى بالمعنى الصحبح وفى المقابل يجب تحديد مسئولبة الوزراء و تقعيل قانون محاكمنهم (51). ـ الحزب التاصرى: 
اما الاصلاح السباسى فى برنامج الحزب العربى الناصرى كما يقول (احمد حسن) الامبن العام للحزب فتنلخص اهم نقاطه كالتالي:

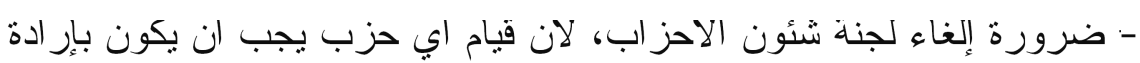
مؤسسية ومو اققة الجماهير . - تعديل الاساسيات و المداخل الضرورية الخاصة بالدستور، وليس التعديل الكامل له كي لا تتحجج الحكومة بان الظروف الحالبة لا تسمح بتغيير الدستور . - اهمية نو افر مبدا تكافؤ الفرص بين الاحزاب، لانه ليس من المنطق ان بسنولي الحزب الحاكم على كل ممتلكات الحزب الاشتر اكى سو اء كانت مباني او اموال، فى حين ان احز اب المعارضة تستاجر مقار اتها فى المحافظات بما فيها المقر الرئيس. - ضرورة إعادة النظر فى قانون مفصل بحدد سلطات الوز ارات و امو ال الدولة و املاكها، وان تكون هناك رقابة لحماية هذه الامو ال مع وجود شفافية مطلقة، لان السلطة النى تثتع بها الحكومة حالبا ادت إلى استيلائها على اموال المعاشات و التامينات ووضعها فى بنك الاستتمار تم قبامها بالسحب من تلك لك

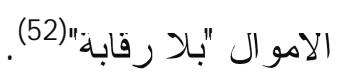

ولا نريد الإطالة في هذا الجانب على اعتبار ان قوى المعارضة الاخرى لايتعدى سقف توجهاتها الاصلاحبة ماذكرناه.

\section{5 -مسقل الإصلاح السياسي في مصر:}

بتمحور الجدل الدائر حول مسنقل الإصلاح السياسي فـ مصر حول الحزب الحاكم وخططه للتجديد والإصلاح لكننا نجد ان الكتير من هذا الجدل قد فقد البوصلة إن جاز التعبير ، إذ إتجه إتجاهاتشتق لاتقود إلى جوهر 
الموضوع و إستكثاف حقيقه، بل يمكن ملاحظة ان اساس هذا الجدل فهسه قد فقد الإتجاه الصحيح إذ إعتبر ان هناك املا في ان بسارع الحزب الحاكم بإجر اء إصلاحسيلسي حقيقي و اسع النطاق فى الوقت الر الهن يشهل فيما يشل تعديل الدستور و الحد من سلطات ومدة حكم الرئيس، و إجر اء إنتخابات نزيهة و إلغاءحالة الطوارئ، و إطلاق سر اح المعتقلين السياسبين (53). و انطلقت هذه الامال رغم ان اي تحليلسيلسي دقيق بخلص إلى إستحالة ان ففل الحزب الحاكم ذلك في ضوء المتغيرات السياسية الراهنة، لإن هذا

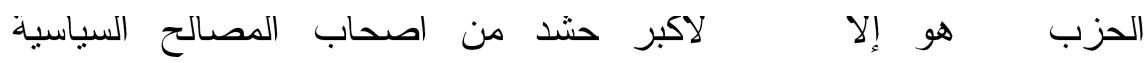

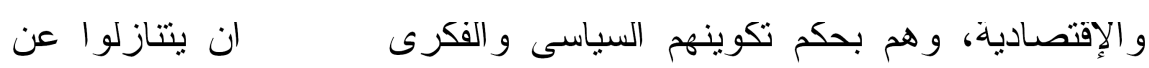

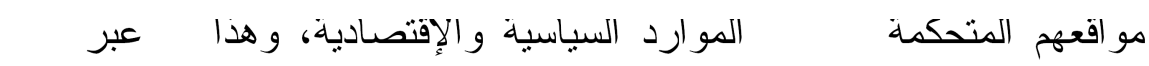
(جمل مبارك) بصر احة ودون ادنى مواربة حين قل: "إن القيادة يجب ان لاتوجهها إسنطلاعات الر ایى العام و إنما مصلحة المجتمع قل ذلك فـ كلمته في

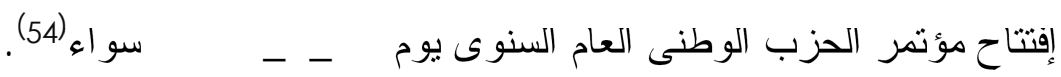
و هذه هـ الازمة فى مصر ، فالثعب ربما بعلق اماله فى الإصلاح على الحزب الحاكم او على قوى المعارضة بينما الحزب الحاكم لاينوي ان يتتازل

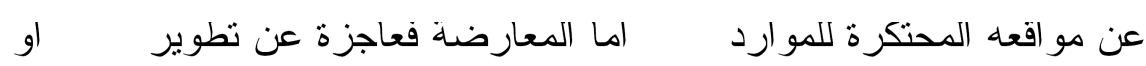
النعاون الخلاق فيما بينها فضلا عن إلز ام الحزب الحاكم بالنطوير و الإصداح. و الحزب الحاكم ينافس احزاب المعارضة فى كل هذه السلبيات غير انه يتفوق عليها بشع و احد الا وهو سبطرته على مقالبد السلطة وتمسكه بها بكل صلابة، ومن ثم التقاف لكل اصحاب المصالح المشروعة حينا وغير المشروعة احيانا اخرى؛ مما اعطاه مظهر الحزب ذي القاعدة الشُعبية مما يجعله ممسكا بزمام 
الامور بقبضة من حديد لكنها تزتدى قفاز ا من حرير، وسيستمر كذلك مالم بحدث احد الإحتمالات التالية:

_الإحتمال الاول: ممارسة ضغوط قوية ومحددة الاهداف من الغرب لإرساء الديمقر اطية والإصـلاح الدستوري، وهذا الإحتمال بعيد كما انه معقد ومنتابك مع منغبر ات كتبرة؛ لان الغرب بلين مع النظام الحاكم بسبب رفضد لوصول الإسلاميين للحكم، وبسبب الخدمات الإسنر اتيجية و الامنية الو اسعة النى لئي

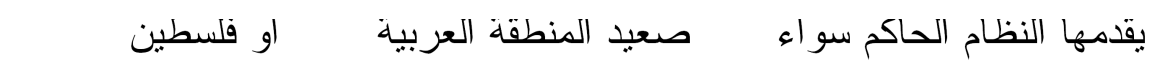
او على صعيد مكلفحة الحركات الإسلامية في إطار ما يسم (بالحرب على

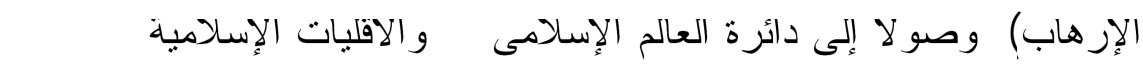

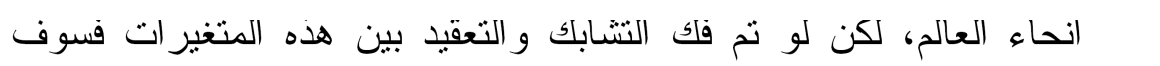
تكون النتيجة واضحة وواسعة النطاق، اما لو استمر النشابك هذا فإن النتيجة سنظل هزيلة. الإحتمال التانى: إدا حدث صر اع داخلى حقيقي على السلطة داخل الحزب الحاكم فهس (وهو امر غبرمستبعد فى حالة مرض او موت الرئبس) فإن ذلك إنك قد يدفع لمزيد من الحريات و الإصداحات لكن فى إطار محدود ولوقت محدود ينتهي بحسم الصر اع على السلطة لصلح احد الاجنحة المتصار عة. الإحتمال النالث: إذا نجحت قوى المعارضة فى النو اقق معا و الضغط باسلوب مناسب من اجل الإصلاح بشكل بلزم الحزب الحاكم بتنفيذ مطالبها كليا

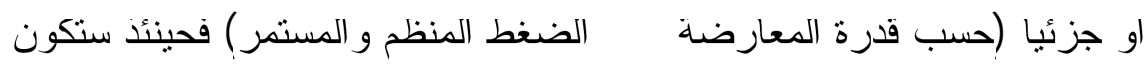
النتيجة كما تريد المعارضة وحسب ما ثتو افق عليه مع الحزب الحاكم من إصلاحات (55).على الرغم ان ما نم تحقيقه لايلبي الطموح، الا انه يمثل خطوة يجب التمسك بها وتطويرها، لان النزاجع يعني الانتكاسة وعودة بعملية 
الاصلاح الى المربع الاول، وهناك خطوط متفاونة لتحقيق ايا من من الامرين، ومن المؤكد ان مسألة التطوير هي الاهم و الاكتر تعقبدا(56).

\section{خاتمة}

جاءت التعديلات الدسنورية في مصر لنسلط الضوء على كثبر من جو انب

الحياة السياسية في هذا البلد العربي المهم، وتكثف النقاب عن كثير من المتتاقضات، فجمهورية مصر العربية تتبنى مبدا فصل الدين عن الدولة وتعلن عن العمل الديمقر اطي في الحياة الحزبية، الا ان الحزب الحاكم يمسك بزمام الامور والاحز اب الاخرى ماهي الا مكمات للصورة الديمقراطية، الا ان

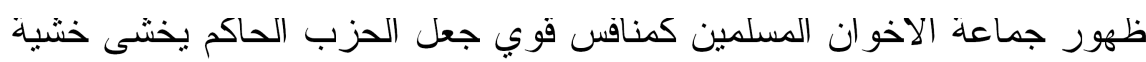
حقبقية بعد سنوات من التقرد بالحكم، و الغريب ان النظام المصري للايسمح للاخوان نكوين حزب وهم باتو بملكون (rr\%) من مقاعد البرلمان، وبهذا فالدولة تصادر مطلب قطاع و اسع من الناخبين المصريين، فادا ار ادت الحكومة المصرية ان تلتزم بما الزمت به نفسها فعليها القبول بافرازات الديمقر اطية، و الا فهي بذلك نظام شمولي يفرض على الشعب رؤيته ويفكر بدلا عنه، ولو

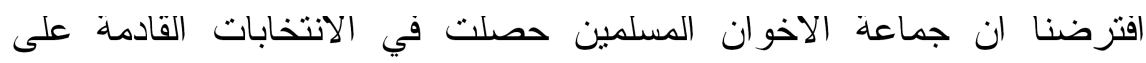

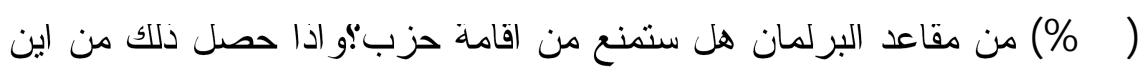

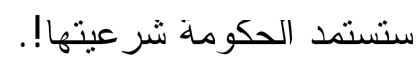
وفي مقابل ذلك يصدر تصريح لشيخ الازهر (سبد طنطاوي) يجعل كل من لايشارك في الاستفتاء على التعديلات (اتم) و الحكومة لاتعد ذلك تدخلا للادين

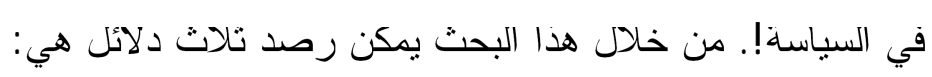
ــ ان الحزب الوطني ليس قابلا للإصلاح من داخله وغير مؤهل لقبادة مشروع سلمي للتحول. 
ــان قوى الخارج لا بمكن إلا ان تكون عبئا على اي عملية إصلاحية في هذه

$$
\text { المنطقة من العالم، وان الرهان عليها خاسر بطبيعنه. }
$$

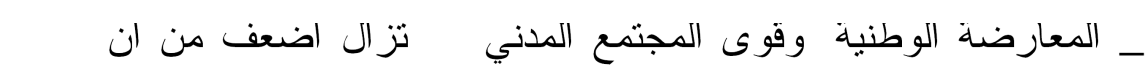
قوة ضغط يمكنها إجبار الحزب الحاكم علي طرح مشروع جدي للإصداح السياسي كذلك عاجزة في الوقت نفسه عن ان تقود بفهها مشروعا للإصلاح و التغيير، باستنتاء الاخوان المسلمين الذين كسبوا ارضا من الصعب ان بفرطو .6 .

I. خلاصة القول لايمكن ان نتجاوز التغيرات الني ظهرت على المشهد السياسي المصري، فقد شهدت الساحة السياسية المصرية حر اكا نشطا لابد ان ينعكس على ارض الو اقع بتغيرات إصلاحية، فعلى الرغم من نجاح الحكومة المصرية في امتصاص جزء كبير من الضغوط الخارجية و الداخلية المطالبة بالتغيير، إلا ان هذا النجاح لايتوقع له ان بسنمر طويلا

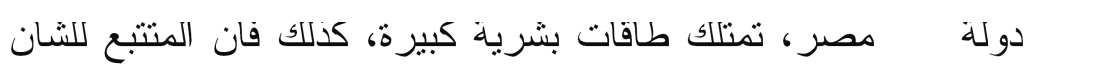
المصري يتوقف عند المكاسب التي حصل عليها الإخوان المسلمين في السنوات القليلة الماضية، و المتمتلة في كسب ثمة الجماهير الني جعلته منافسا هققا للحزب الحاكم رغم النضبيق الذي بمارس عليه، مما بعطي انطباعا و اضحا ان المستقبل القريب من الممكن ان بشهذ تعدديةسيلسية حقيقية، ومشاركة في صنع القر ار. 


\title{
The Future of political Reform In Egypt: Reality And Ambition
}

\author{
Mithaq Khyrallah Jalud \\ Assistant Lecturer/ Department Of Historical \& Cultural Studies, \\ Regional Studies Center, Mosul University
}

\begin{abstract}
The issue of reform in Egypt is considered on urgent issue as the rest of countries in the Arab Homeland In this respect, Egypt had witnessed during the last three years significant political changes Egypt after 2005 came through an amendment of (34) articles of the constitution and the most important of which is the article No.(76) of electing a Candidate for the presidency post. with regard to legislative elections, it recorded a new stage for the ruling party and its candidates got only (33.5\%) of the seats in side the parliament whereas candidates of moslem Brotherhood got about (22\%) in the parliament and it was an important event in the political life in Egypt.

Controversy inside political media in Egypt is turning about the ruling party and its plans for reform but we could find that most of that controversy does not come in the right direction..
\end{abstract}


(1)"Political Reform in Egypt",all academic research:

www.allacademic.com

(2)U.S.A., President Bush,The White House: www.whitehouse.gov

(3) Joseph Krauss," US STILL URGING REFORM INEGYPT",

The Christlan Science Monitor,23 February2006:

www.csmonitor.com

(4) هيفاء احمدمحمد،"الاصلاح السياسي في مصر في ظل الانتخابات الرئاسية الاخيرة"، بحلة دراسات

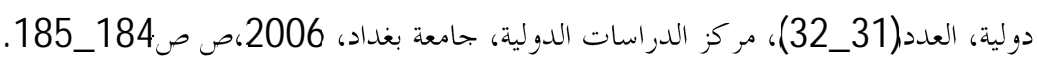

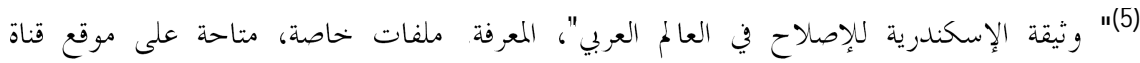

الجزيرة:WWW.ajjazzera net؛ محمد، المصدر السابق، ص186.

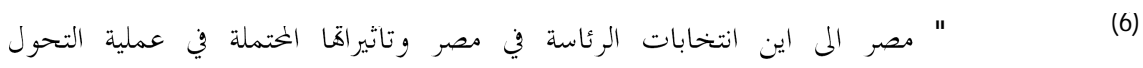

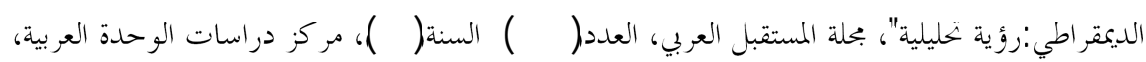

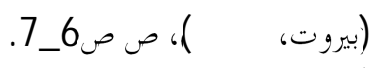

(/) "خصائص نظام الحكم المصري من منظور علم السياسة"، المعرفة، ملفات خلصة، متاهة على مقع

$$
\text { حسين عبد الرزاق،" صلاحيات رئيس الجمهورية" مقال متاح على الموقع : }
$$

http://www.eohr.org/ar/report/2005/k5.html

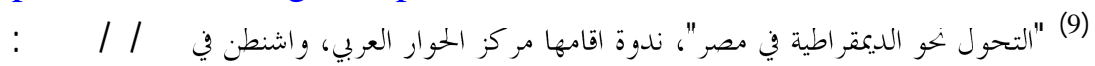

www.arabgate.com/printmore

$$
\begin{aligned}
& \text { (10) خصائ نظام الحكم، المصدر السابق. } \\
& \text { (11) التحول نهو الديمقراطية، المصدر السابق. } \\
& \text { (12) خصأص نظام الحكم، المصدر السابق. }
\end{aligned}
$$

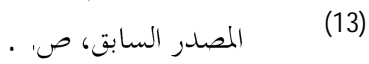

$$
\begin{aligned}
& \text { (14) خصأص نظام الحكم، المصدر السابق. }
\end{aligned}
$$

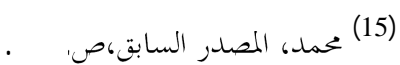




$$
\begin{aligned}
& \text { (16) خحائص نظام الحكم، المصدر السابق. }
\end{aligned}
$$

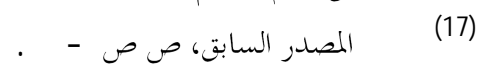

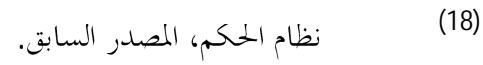

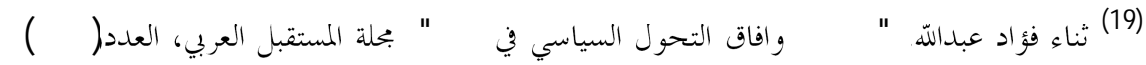

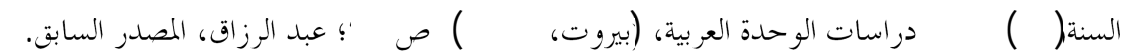

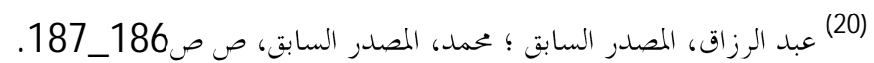

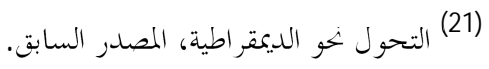

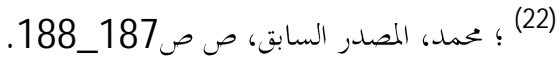

$$
\begin{aligned}
& \text { (23) جسن نلفة، " الحصاد المر"، مقال متاح على موقع مر كز القاهرة لدراسات وحقوق الانسان: }
\end{aligned}
$$

http://www.cihrs.org/opinion_details_ar.aspx?op_id=11

$$
\text { (24) "مسيرة الاصلاح السياسي في مصر"، الموقع الرسمي بخلس الشورى المصري: }
$$

http://shura.sis.gov.eg/ahtml/link06.htm

$$
\begin{aligned}
& \text { (25) محمد عبد الفتاح الحمراوى،" الاصلاح السياسي في مصر بين مطرقة الهيمنة وضغوط الداخل } \\
& \text { بعد11 سبتمبر"، بحلةانكيدو الثقافيةالحرة،3_3 }
\end{aligned}
$$

http://m.ankido.us/news.php?action=view\&id

$$
\begin{aligned}
& \text { (26) الموقع الرسمي بخلس الشورى المصري. }
\end{aligned}
$$

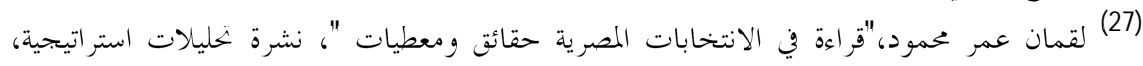

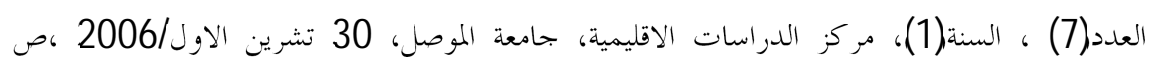

$$
\begin{aligned}
& \text { ص } \\
& \text { 2005_9_12 (28) صحيفة الزمان، العدد(211)، }
\end{aligned}
$$

(29) Dan Murphy, Egyptian government steps up attacks on VOTERS,The Christlan Science Monitor,9 December2005: www.csmonitor.com

$$
\text { (30) معلومات متاحة على الموقع: }
$$

http://www.ahrla.org/elmarsad_ar/76th/awrak.htm 


$$
\begin{aligned}
& \text { (32) حسنين توفيق ابراهيم و حامد عبد الماجد قويسي،" الانتخابات التشريعية ومستقبل التطور السياسي }
\end{aligned}
$$

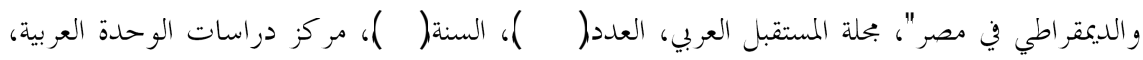

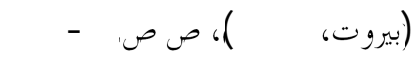

Özlem Tur Kavlı,"Islamic Movements in the Middle East Egypt as a Case Study",Perceptions JORNAL OF Internatial Affairs,Vol.(VI),(Ankara,2002),P32.

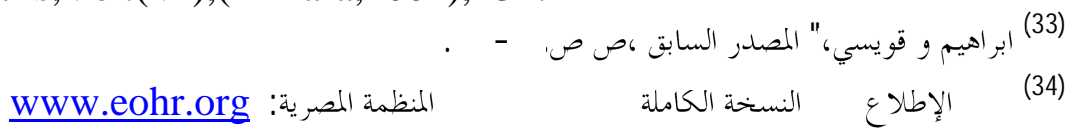
(35) Murphy,Op.Cit.

$$
\text { (36) الموقع الرسمي للكتلة البرلمانية للاخو ان المسلمين: }
$$

http://www.nowabikhwan.com/

$$
\text { "(37) "محاولة لفهم الاخوان"، مقال متاح على الموقع: }
$$

fsid=665\&http://www.aeamisr.org/modules.php?name=News

$$
\begin{aligned}
& \text { (38) محمد، المصدر السابق، ص190. } \\
& \text { (39) محاولة لفهم الاخوان، المصدر السابق. } \\
& \text { معلومات متاحة على الموقع: }
\end{aligned}
$$

http://dedi.org.eg/index.php?id=1

(41) "ا دور القضاة في الاصلاح السياسي في مصر والعالم العربي"،معلومات مقال متاحعلى مقع المنظمة

$$
\text { السورية لحقوق الانسانرنسواسية): }
$$

http://www.hrinfo.net/syria/sohr/2006/pr0418.shtml

$$
\begin{aligned}
& \text { (42) تحدث في الندوة الدكتور رشديسعيد، العالم المصري في بحال الجيولوجيا وعضو بحلس الشعب المصري }
\end{aligned}
$$

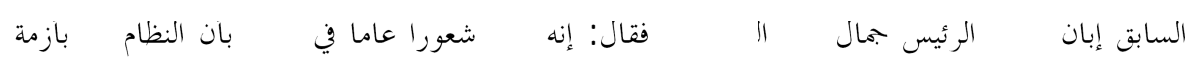

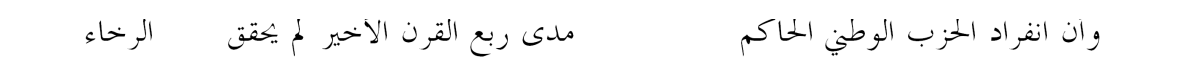

$$
\begin{aligned}
& \text { فثلل النظامعلى كلى المستويات، التحول نحو الديمقر اطية، المصدر السابق. } \\
& \text { (43)1، اصلاح النظام الانتخابي في مصر الضرورات والاليات"،مقال المقال متاح على موقع المنظمة المصرية. }
\end{aligned}
$$

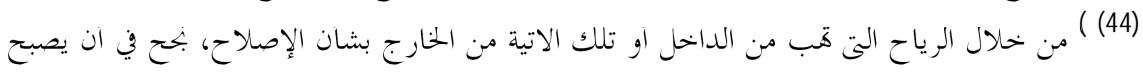

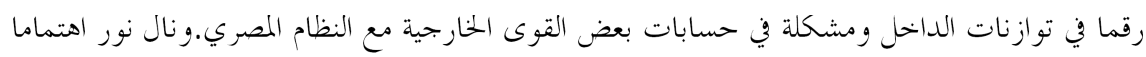




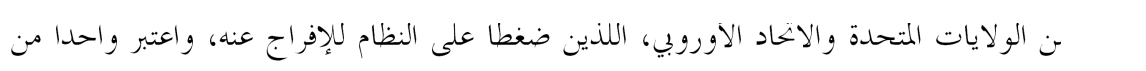

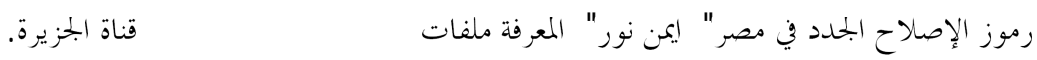

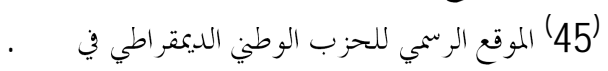

http://dedi.org.eg/index.php?id=1

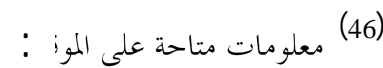

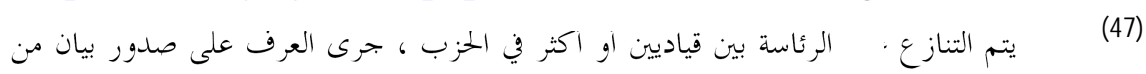

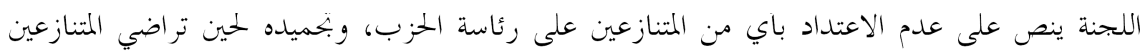

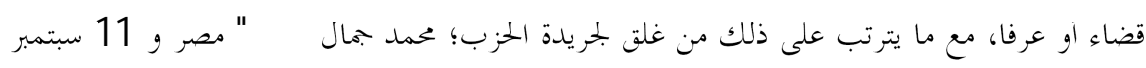

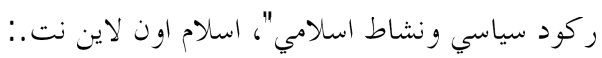

http://www.islamonline.net/arabic/politics/2002/09/article

(48) مبادرة المرشد العام للإخوان المسلمين حول المبادئ العامة لإصلاح في مصر، متلحة على

http://www.kefaya.org/publications.htm

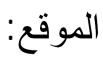
http://www.alwafdparty.com

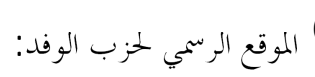

$$
\text { (50) الاصلاح السياسى في مصر بين الواقع، المصدر السابق. }
$$

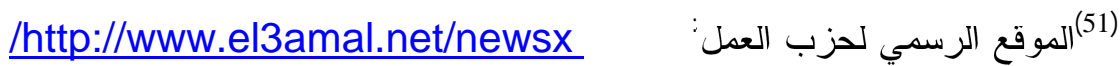

$$
\text { (53) (52) الاصلاح السياسي لفيل الرسي مصر بين الو اقع المصدر السابق. }
$$

http://moneep.katib.org/node/27

$$
\text { 2004_9_22_(54) صحيفة الحياة) }
$$

$$
\text { (55) مستقبل الإصلاح السياسى فن مصر"، مقال متاح على الموقع: }
$$

http://moneep.katib.org/node/27

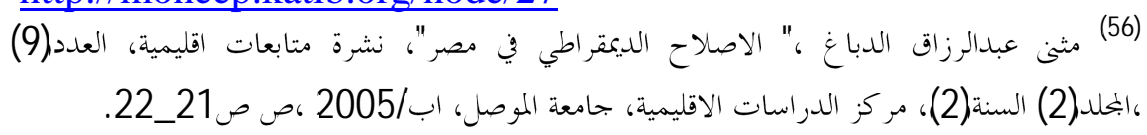

